\title{
New Mechanism on Synergistic Effect of Nitrite and Triethanolamine Addition on the Corrosion of Ductile Cast Iron
}

\author{
K. T. Kim, ${ }^{1}$ H. Y. Chang, ${ }^{2}$ B. T. Lim, ${ }^{2}$ H. B. Park, ${ }^{2}$ and Y. S. Kim ${ }^{1}$ \\ ${ }^{1}$ Materials Research Centre for Energy and Clean Technology, School of Materials Science and Engineering, \\ Andong National University, 1375 Gyeongdongro, Andong, Gyeongbuk 36729, Republic of Korea \\ ${ }^{2}$ Power Engineering Research Institute, KEPCO Engineering \& Construction Company, No. 269, Hyeoksinro, \\ Gimcheon, Gyeongbuk 39660, Republic of Korea
}

Correspondence should be addressed to Y. S. Kim; yikim@anu.ac.kr

Received 26 May 2016; Revised 25 August 2016; Accepted 28 August 2016

Academic Editor: Paolo Ferro

Copyright (C) 2016 K. T. Kim et al. This is an open access article distributed under the Creative Commons Attribution License, which permits unrestricted use, distribution, and reproduction in any medium, provided the original work is properly cited.

\begin{abstract}
In general, we compared the different inhibition mechanisms of organic inhibitor with that of anodic inhibitor. When triethanolamine or nitrite was added separately to tap water for inhibiting the corrosion of ductile cast iron, large amounts of inhibitor were needed. This is because the corrosion inhibitors had to overcome the galvanic corrosion that occurs between graphite and matrix. In this work, we investigated the corrosion of ductile cast iron in tap water with/without inhibitors. The corrosion rate was measured using chemical immersion test and electrochemical methods, including anodic polarization test. The inhibited surface was analyzed using EPMA and XPS. Test solutions were analyzed by performing FT-IR measurement. When triethanolamine and nitrite coexisted in tap water, synergistic effect built up, and the inhibition effect was ca. 30 times more effective than witnessed with single addition. This work focused on the synergistic effect brought about by nitrite and triethanolamine and its novel mechanism was also proposed.
\end{abstract}

\section{Introduction}

Recently, many research studies have reported about the different kinds of corrosion in nuclear power plants. In a nuclear power plant, the length of pipelines is approximately 30 $40 \mathrm{~km}$. These pipelines are installed and operated on a regular basis in a nuclear power plant: and each pipeline is separately maintained by taking into consideration the application system and internal water chemistry. Such pipelines usually get damaged due to corrosion, which should be tackled immediately and effectively [1]. The safety and soundness of these pipelines are increased remarkably by the following factors: corrosion, growth of microorganisms, and fouling. In order to mitigate the problems caused by corrosion, cathodic protection and corrosion inhibitors are applied [2-4].

In general, 3 kinds of corrosion inhibitors have been used in engineering fields [5]. Anodic inhibitors increase the potential of the metal or alloys up to the critical protection value. They are called anodic passivating inhibitors. On the other hand, cathodic inhibitors increase the cathodic polarization overvoltage (hydrogen and oxygen reduction). Thick deposits form in the presence of these inhibitors and decrease depolarizer diffusion to the metal surface, inhibiting the cathodic reaction and corrosion. Organic inhibitors contain sulfur, nitrogen, or oxygen atoms and organic heterocyclic compounds containing polar groups [610]. These compounds adsorb and form a covalent bond on the metal surface [11]. They may also act as a barrier film by blocking anodic and cathodic active sites or decreasing electroactive species transport rate to or from the metal surface.

Corrosion inhibitors, such as nitrite, chromate, silicate, molybdate, and hydrazine, are usually used for mitigating problems caused by corrosion. It has been reported that these chemicals are quite effective in inhibiting corrosion $[13,14]$. In a previous study [12], we described the corrosion inhibiting mechanism of nitrite ion on the passivation of carbon steel and ductile cast iron (DCI) in nuclear power plants: the corrosion of carbon steel and DCI is immensely mitigated by the addition of $\mathrm{NaNO}_{2}$. In order to ensure similar corrosion 
TABLE 1: Chemical composition of the experimental alloy.

\begin{tabular}{lcccccccrrr}
\hline Material & \multicolumn{1}{c}{} & \multicolumn{4}{c}{ Chemical composition, wt\% } & & \\
& $\mathrm{C}$ & $\mathrm{Mn}$ & $\mathrm{P}$ & $\mathrm{S}$ & $\mathrm{Si}$ & $\mathrm{Cu}$ & $\mathrm{Mo}$ & $\mathrm{Ni}$ & $\mathrm{V}$ \\
\hline $\begin{array}{l}\text { Ductile cast iron } \\
(\mathrm{DCI})^{*}\end{array}$ & 4.008 & 0.173 & 0.022 & 0.026 & 1.528 & 0.023 & 0.028 & 0.059 & 0.016 & bal. \\
\hline * & & & & & & &
\end{tabular}

${ }^{*}$ KS D4311.

resistance, ca. 100 times more $\mathrm{NaNO}_{2}$ addition is needed for DCI than for carbon steel. Nitrite, which is one of the representative anodic inhibitors, inhibits corrosion by forming a $\mathrm{Fe}_{2} \mathrm{O}_{3}$ oxide film on the metal surface [15-22]. The $\mathrm{NO}_{2}{ }^{-}$ion is reduced to nitrogen compound and this compound is easily adsorbed on the surface of graphite. In summary, nitrite ion is required to oxidize the surface of matrix: it is also required to passivate the galvanic corroded area. Moreover, since it is adsorbed on the surface of graphite, a greater amount of corrosion inhibitor has to be added to DCI than to carbon steel. Furthermore, a passive film of carbon steel and DCI is formed after the addition of $\mathrm{NaNO}_{2}$ : this film shows $\mathrm{N}$-type semiconductive properties and greater resistance. Consequently, the passive current density of the film decreases. Thus, the rate of corrosion is decelerated in this film.

However, to inhibit the corrosion of DCI in tap water, it is not advisable to add 100k ppm nitrite in engineering fields: the concentration of nitrite should be minimized in this case. Nevertheless, when two kinds of corrosion inhibitors coexist, a synergistic effect is achieved [23-26]. Although researchers reported extensively about this synergistic effect, they could not clearly elucidate the mechanism through which this synergistic effect was elicited. This work focused on how the synergistic effect of nitrite and triethanolamine (TEA) inhibited the corrosion of DCI. TEA, as an organic inhibitor, inhibits corrosion by forming adsorption layer [27, 28]. Adsorption layers depend upon the metal microstructure, inhibitor concentration $[29,30]$, chemical structure, $\mathrm{pH}[31]$, temperature $[32,33]$, and immersion time $[34,35]$. The combination of two inhibitors was evaluated using chemical and electrochemical methods. Therefore, we proposed the mechanism of the synergistic effect elicited by two inhibitors.

\section{Experimental Procedure}

2.1. Materials and Corrosion Environments. DCI (KS D4311) [36] was used in this work. Table 1 shows the chemical composition of experimental alloy. The test solution was tap water. Nitrite (as $\mathrm{NaNO}_{2}$ ) and TEA were added in concentrations of the order of ppm.

\subsection{Corrosion Tests}

2.2.1. Immersion Corrosion Test. A specimen was cut to a size of $20 \times 20 \times 5 \mathrm{~mm}$ and each surface of this specimen was ground using \#120 SiC paper. Immersion tests were conducted in $500 \mathrm{~mL}$ glass flask containing stagnant solution. Test solutions were tap water with $x$ ppm corrosion inhibitors. Corrosion inhibitors were sodium nitrite and triethanolamine. Test temperature was $25^{\circ} \mathrm{C}$. After performing the immersion test, each specimen was cleaned with acetone and alcohol. Then this specimen was dried. Finally, the corrosion rate of this specimen was determined.

2.2.2. Electrochemical Tests. Specimens were cut to a size of $20 \times 20 \mathrm{~mm}$. After connecting these specimens in an electrical circuit, they were epoxy-mounted. Then, the surface of these specimens was ground using \#600 SiC paper. Finally, these specimens were coated with epoxy resin, except an area of $1 \mathrm{~cm}^{2}$. A polarization test was performed using a potentiostat (DC 105, Gamry Instruments), the reference electrode was a saturated calomel electrode, and the counter electrode was Pt wire. Test solutions were tap water with $x$ ppm corrosion inhibitors. Corrosion inhibitors were sodium nitrite and triethanolamine. Test temperature was $25^{\circ} \mathrm{C}$. The test solution was deaerated using nitrogen gas: this gas was purged at a rate of $200 \mathrm{~mL} / \mathrm{min}$ into the solution for 30 minutes. The scanning rate was $0.33 \mathrm{mV} / \mathrm{sec}$. In order to measure the $\mathrm{AC}$ impedance, the specimens were ground using \#2,000 $\mathrm{SiC}$ paper. Then, these specimens were polished using a diamond paste (its diameter was $3 \mu \mathrm{m}$ ). The test solution was the same as that used in polarization test. To measure AC impedance, we used an electrochemical analyzer (EIS300, Gamry Instruments). Before measuring AC impedance, passivation was performed on DCI at $+200 \mathrm{mV}$ and $0 \mathrm{mV}$ (SCE) for 30 minutes. AC impedance was measured ranging from $10 \mathrm{kHz}$ to $0.01 \mathrm{~Hz}$ and the AC voltage amplitude was $10 \mathrm{mV}$. Thereafter, a MottSchottky plot was constructed to determine the semiconductive properties of the passive film. The specimen preparation was the same as that used in the measurement of $\mathrm{AC}$ impedance, and the DC amplitude was $10 \mathrm{mV}$ (peak-topeak) at $1,580 \mathrm{~Hz}$ of $\mathrm{AC}$ frequency [37]. The capacitance was measured at a scan rate of $50 \mathrm{mV} / \mathrm{sec}$ : the potential was varied between $+1 \mathrm{~V}(\mathrm{SCE})$ and $-1 \mathrm{~V}(\mathrm{SCE})$.

2.2.3. Surface Analysis. X-ray Photoelectron Spectroscopy (XPS, K-alpha (Thermo VG, UK), Al-K $\alpha(1486.6 \mathrm{eV}, 12 \mathrm{kV}$, and $3 \mathrm{~mA}$ )) was performed to determine the chemical state of several species in the passive film. The specimen was cut to a size of $20 \times 20 \times 5 \mathrm{~mm}$, and it was ground with \#2000 SiC paper. Thereafter, it was polished with a diamond paste, which was $3 \mu \mathrm{m}$ in diameter. Finally, the specimen was cleaned with alcohol using an ultrasonic cleaner. DCI was passivated by immersing it in 100,000 ppm $\mathrm{NO}_{2}{ }^{-}, 100,000 \mathrm{ppm} \mathrm{TEA}$, and $3,500 \mathrm{ppm} \mathrm{NO}_{2}{ }^{-}+\mathrm{TEA}$, respectively. The immersion process was carried out for 72 hours. The depth profile was obtained every 5 seconds by Ar-sputtering. In addition, an Electron 


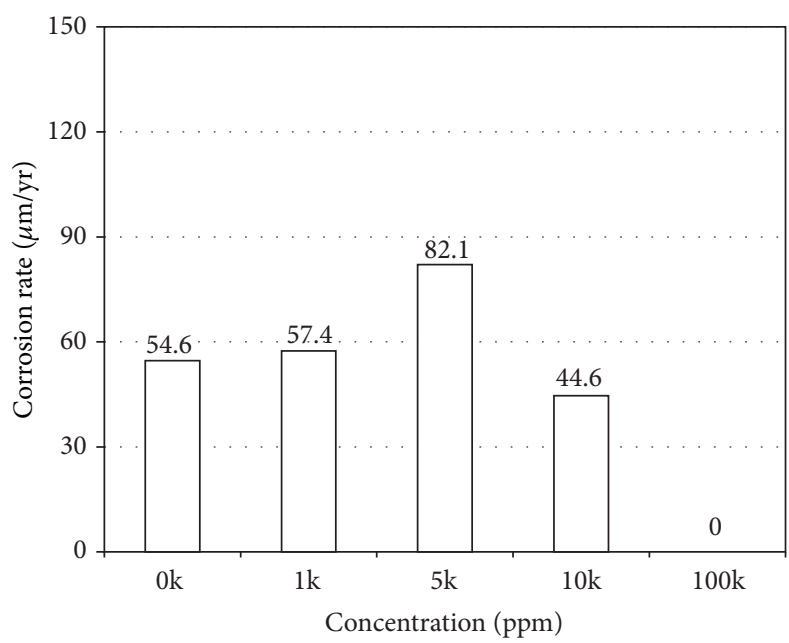

(a)

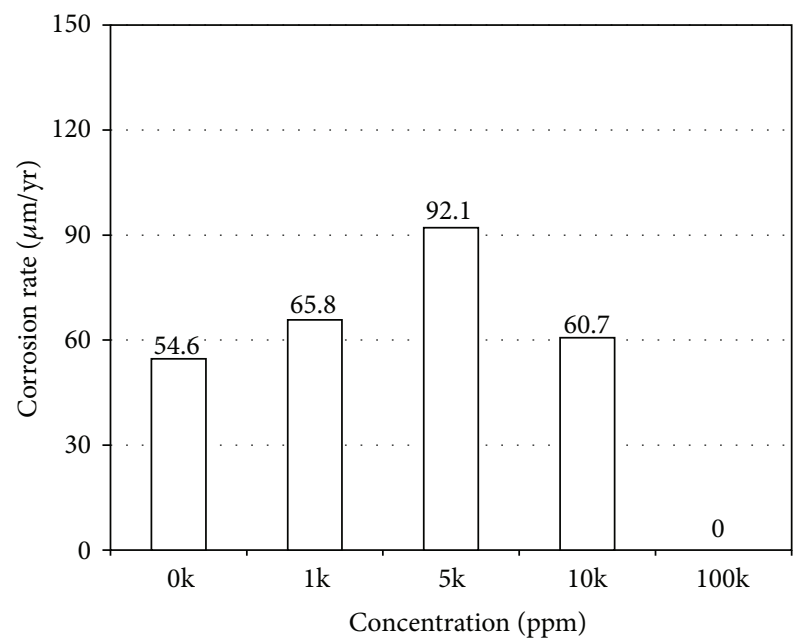

(b)

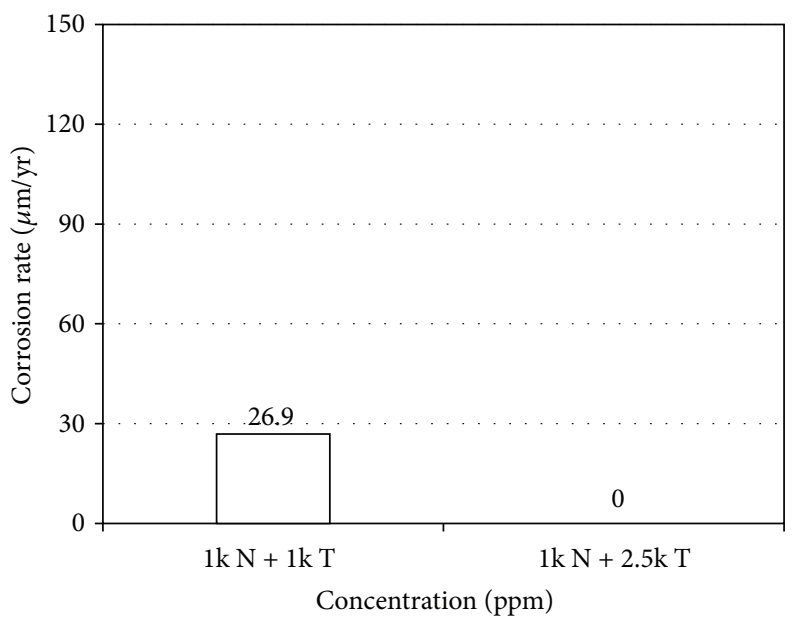

(c)

FIGURE 1: The effect of single addition and coaddition of corrosion inhibitor on the corrosion rates of DCI $\left(25^{\circ} \mathrm{C}\right.$ tap water $+x$ ppm corrosion inhibitor). (a) $\mathrm{NO}_{2}^{-}$, (b) TEA, and (c) $\mathrm{NO}_{2}^{-}+$TEA.

Probe Microanalyzer (EPMA, EPMA-1600, 15 KV) was used to identify the elemental distribution of passivated surface. Optical Microscope (OM, Zeiss Axiotech $100 \mathrm{HD}$ ) and scanning electron microscopy with energy dispersive X-ray spectroscopy (SEM (Tescan Vega II LMU) EDS (OXFORD ISIS-300)) were used. Furthermore, to investigate the surface compounds, FT-IR (Fourier Transform-Infrared Spectrophotometer, Nicolet 6700, Thermo Nicolet, USA) analysis was performed.

\section{Results}

Nitrite is one of the representative anodic inhibitors, while TEA is one of the organic inhibitors. As reported earlier $[38,39]$, nitrite can inhibit the corrosion of DCI in tap water; however, a large amount of nitrite was needed to completely mitigate corrosion. Therefore, we tried to develop a novel method that inhibits corrosion effectively. Figure 1 shows the effect of single and coexisting corrosion inhibitors on the corrosion rates of DCI in tap water at $25^{\circ} \mathrm{C}$ (in this paper, $\mathrm{N}$ means a nitrite and $\mathrm{T}$ implies TEA: $1 \mathrm{k} \mathrm{N}$ represents $1,000 \mathrm{ppm}$ nitrite). When tap water did not contain any corrosion inhibitors, the corrosion rate of DCI was $54.6 \mu \mathrm{m} / \mathrm{y}$. When 5,000 ppm of corrosion inhibitors was added to tap water, the corrosion rates of DCI increased regardless of the concentration of nitrite or TEA. However, with the addition of 10,000 ppm of corrosion inhibitors, the corrosion of DCI decreased. Nevertheless, the corrosion rates of DCI were still relatively high. Finally, with the addition of $100,000 \mathrm{ppm}$ of corrosion inhibitors, the corrosion of DCI was completely inhibited in tap water. However, such a high concentration of corrosion inhibitors was not a practical solution in engineering aspects. On the other hand, the coaddition of nitrite and TEA greatly reduced corrosion of DCI in tap water; the coaddition of 1,000 ppm nitrite and 1,000 ppm TEA brought down the corrosion rate to $26.9 \mu \mathrm{m} / \mathrm{y}$. Finally, the coaddition of 1,000 ppm nitrite and 2,500 ppm TEA absolutely inhibited the corrosion of DCI in tap water: this occurrence is known 


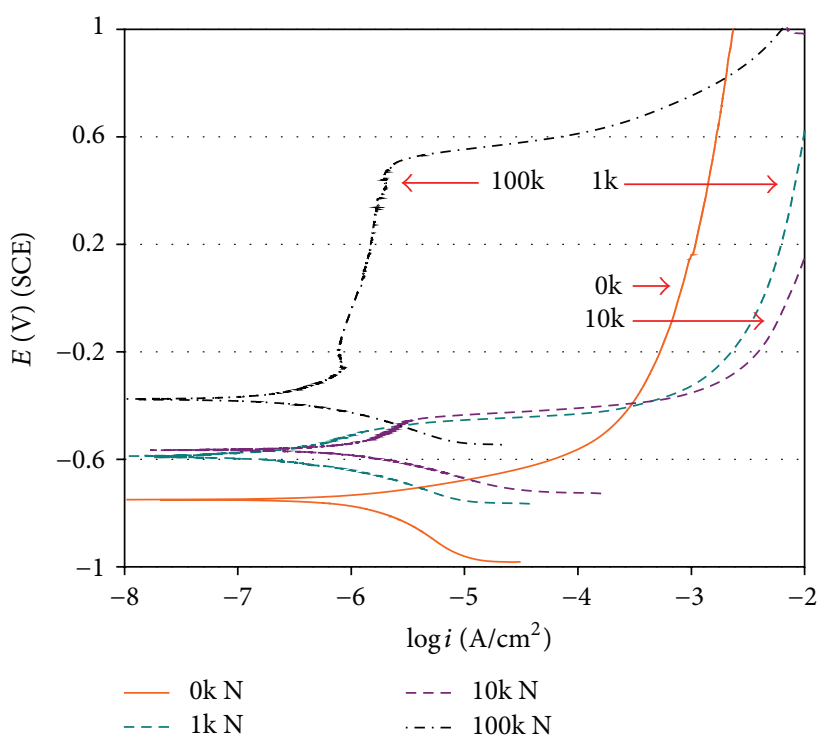

(a)

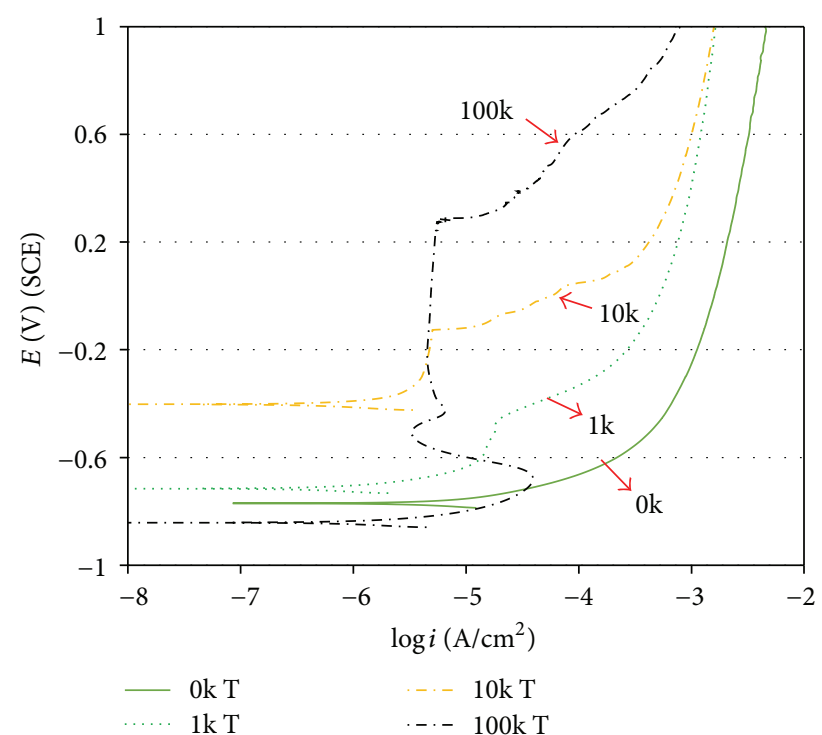

(b)

FIGURE 2: Effect of singly added corrosion inhibitors on anodic polarization curve of DCI $\left(25^{\circ} \mathrm{C}\right.$ deaerated tap water $+x$ ppm corrosion inhibitor ( $\mathrm{N}: \mathrm{NO}_{2}{ }^{-}$, T: TEA)); (a) nitrite addition, (b) TEA addition.

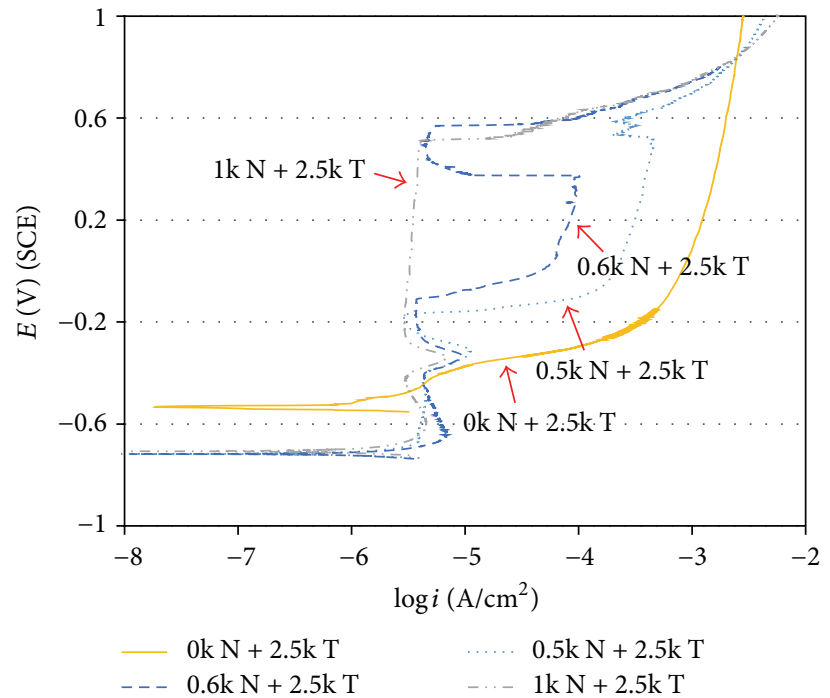

(a)

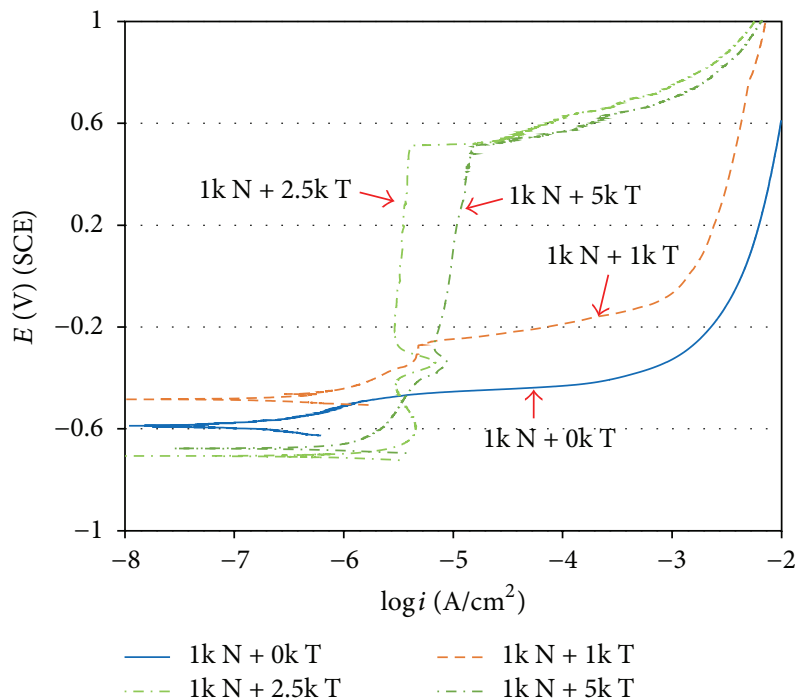

(b)

FIGURE 3: Effect of coadded corrosion inhibitors on anodic polarization curve of DCI $\left(25^{\circ} \mathrm{C}\right.$ deaerated tap water $+x$ ppm corrosion inhibitor $\left(\mathrm{N}: \mathrm{NO}_{2}{ }^{-}, \mathrm{T}\right.$ : TEA)). (a) $2.5 \mathrm{k} \mathrm{ppm} \mathrm{T}+x \mathrm{ppm} \mathrm{N}$, (b) $x \mathrm{ppm} \mathrm{T}+1 \mathrm{kppm} \mathrm{N}$.

as a synergistic effect [12]. We measured the variation in electrochemical polarization at various concentrations of the inhibitor. Figure 2 shows the effect of a single corrosion inhibitor on the anodic polarization curve of DCI in deaerated tap water at $25^{\circ} \mathrm{C}$. When $10,000 \mathrm{ppm}$ of nitrite was added as a single inhibitor, there was an increase in corrosion potential. Moreover, the passive range developed to some extent. Nevertheless, current density increased abruptly due to anodic polarization. Furthermore, when 100,000 ppm of nitrite was added, a stable passive range was formed. This behavior was coincident with the results of chemical immersion test (the results are summarized in Figure 1). On the other hand, when 10,000 ppm of TEA was added, the passive range developed to some extent: however, current density increased abruptly due to anodic polarization. Furthermore, a stable passive range was formed when the concentration of TEA was increased to $100,000 \mathrm{ppm}$. This behavior was in good agreement with the results of chemical immersion test (the results of the test are shown in Figure 1). On the other hand, synergistic effect was produced by the coaddition of nitrite and TEA. This finding was confirmed by performing electrochemical polarization test. Figure 3 shows the effect 


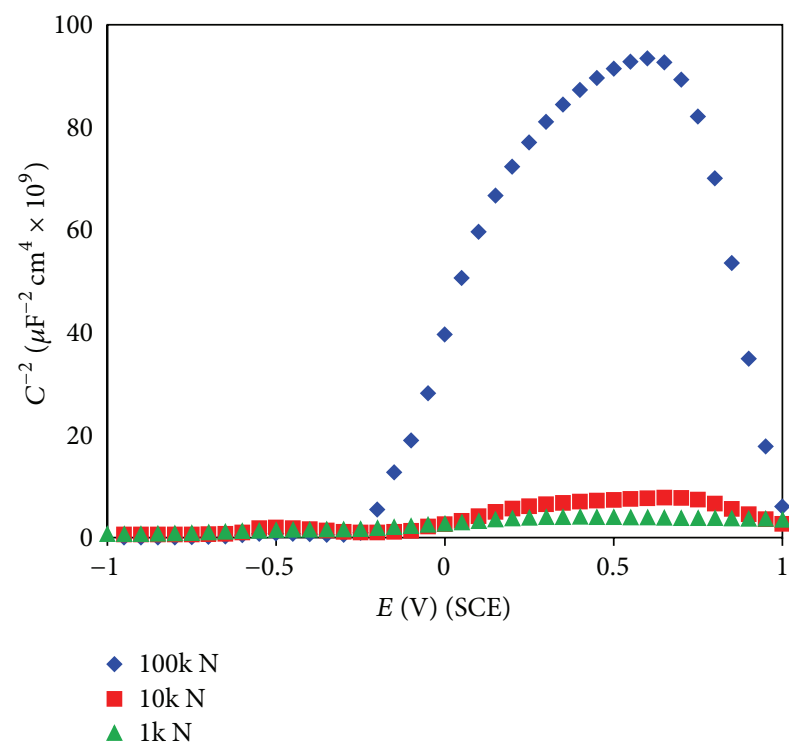

(a)

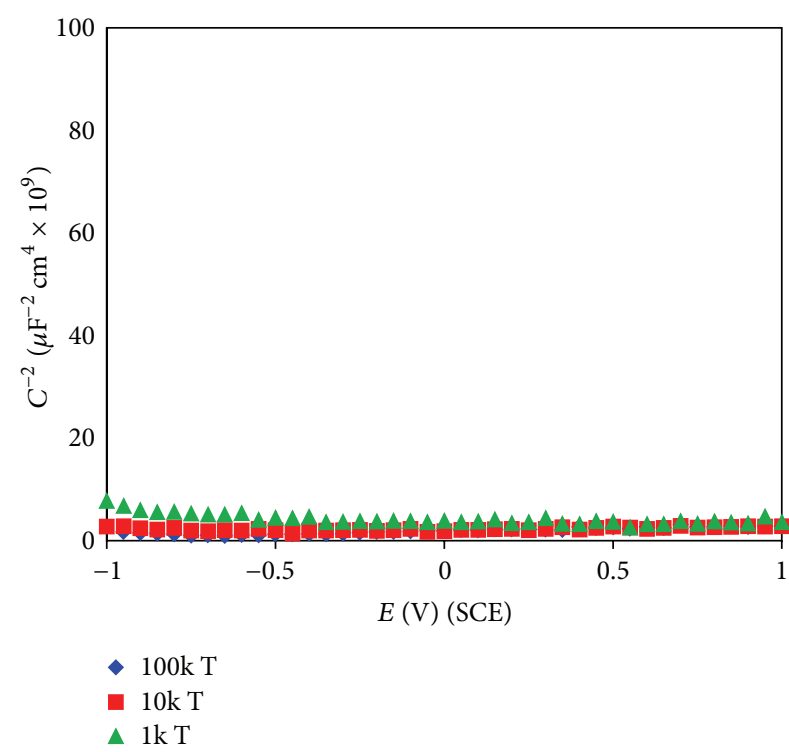

(b)

FIGURE 4: Effect of corrosion inhibitors ( $\mathrm{N}: \mathrm{NO}_{2}{ }^{-}$, T: TEA) on Mott-Schottky plot for the passive film formed at $0 \mathrm{~V}$ (SCE) in deaerated tap water at $30^{\circ} \mathrm{C}$. (a) Nitrite addition. (b) TEA addition.

of coadded corrosion inhibitors on the anodic polarization curve of DCI in deaerated tap water at $25^{\circ} \mathrm{C}$. When nitrite was increased at constant 2,500 ppm TEA, passivation behavior improved. Furthermore, the coaddition of 1,000 ppm nitrite resulted in a stable passive range (Figure $3(\mathrm{a})$ ). In addition, when TEA was increased at constant $1,000 \mathrm{ppm}$ nitrite, passivation behavior improved; the coaddition of 2,500 ppm TEA resulted in a stable passive range (Figure 3(b)). Thus, the electrochemical test proved that the synergistic effect was brought about by the coaddition of nitrite and TEA.

In general, a protective film can be easily formed on the surface by the addition of corrosion inhibitors. Semiconductive properties are exhibited by the passive film formed on the surface: these properties can be evaluated using a Mott-Schottky plot. Figure 4 displays the effect of corrosion inhibitors on Mott-Schottky plot, which represents the surface film formed at $0 \mathrm{~V}$ (SCE) in deaerated tap water at $25^{\circ} \mathrm{C}$. By increasing the concentration of nitrite, $C^{-2}$ values were increased. Interestingly, regardless of the concentration of nitrite, the passive film exhibited only $\mathrm{N}$-type semiconductive properties. However, in the case of TEA addition, capacitance did not develop at any of the concentrations of TEA. Figure 5 shows the effect of corrosion inhibitors on AC impedance, which developed on the surface film that was formed at $0 \mathrm{~V}$ (SCE) in deaerated tap water at $25^{\circ} \mathrm{C}$. Just as in the case of Mott-Schottky plot, AC impedance also increased with an increase in the concentration of nitrite. On the other hand, regardless of its concentration, TEA addition did not cause any impedance. Thus, two corrosion inhibitors prevent the corrosion of DCI through different mechanisms.

After immersing DCI in tap water containing corrosion inhibitors, EPMA analysis was performed and the formation of other materials on the surface was detected. Test solutions were prepared at the concentration that prevented the corrosion of DCI. Figure 6 shows the elemental distribution on the surface of DCI, which was passivated for 72 hours in tap water containing $100,000 \mathrm{ppm}$ of $\mathrm{NO}_{2}{ }^{-}$at $25^{\circ} \mathrm{C}$. The elemental distribution was obtained by performing EPMA analysis of the surface of DCI under these conditions [12]. SEM image of DCI reveals the presence of spheroidized graphite in the matrix. Iron was depleted on the graphite, while carbon was enriched on the spheroidized phase. Oxygen was detected on the matrix, but it was more enriched on the graphite. A little amount of nitrogen was also detected on the graphite (this result has been reported and discussed in an earlier paper [12]). Figure 7 reveals the elemental distribution on the surface of DCI, which was passivated for 72 hours in tap water containing $100,000 \mathrm{ppm}$ of TEA at $25^{\circ} \mathrm{C}$. The elemental distribution on the surface of DCI was obtained by performing EPMA analysis. SEM image also shows the irregular pattern of spheroidized graphite. Iron depleted on the irregular spheroidized phase, while carbon was enriched on the spheroidized phase. Furthermore, oxygen was more enriched on the irregular phase than in the matrix, while nitrogen was enriched on the spheroidized phase. Figure 8 represents the elemental distribution, which was analyzed by EPMA, on the surface of DCI; the surface was passivated for 72 hours in tap water containing $1,000 \mathrm{ppm} \mathrm{NO}_{2}{ }^{-}+$ $2,500 \mathrm{ppm}$ TEA at $25^{\circ} \mathrm{C}$. SEM image shows the spheroidized graphite: iron was depleted on the spheroidized phase; carbon was enriched on the spheroidized phase; oxygen was enriched on the spheroidized phase and also on the matrix, while small amounts of nitrogen were also detected on the spheroidized phase.

\section{Discussion}

As described earlier, when a single addition corrosion inhibitor (nitrite or TEA) is added to inhibit corrosion 


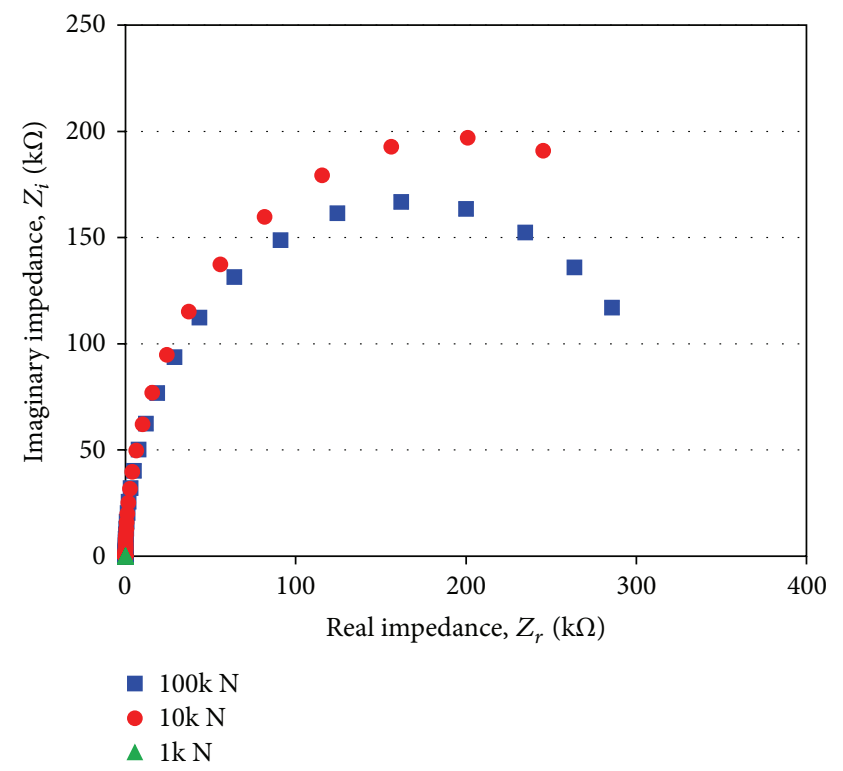

(a)

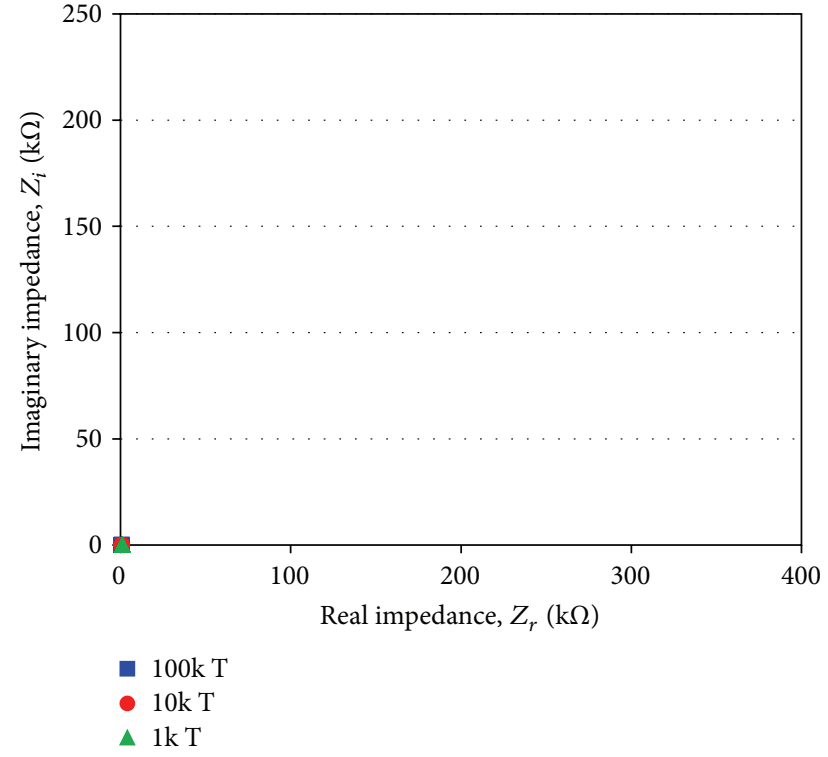

(b)

FIgURE 5: Effect of corrosion inhibitors ( $\mathrm{N}^{\mathrm{NO}_{2}}{ }^{-}$, T: TEA) on AC impedance measurement for the passive film formed at $0 \mathrm{~V}$ (SCE) in deaerated tap water at $30^{\circ} \mathrm{C}$. (a) Nitrite addition. (b) TEA addition.

of DCI in tap water, a very high concentration of the corrosion inhibitor is required. On the other hand, when there is coaddition of a small amount of nitrite and TEA, the corrosion of DCI is effectively inhibited in tap water. Thus, a synergistic effect was achieved with the coaddition of both nitrite and TEA. This kind of synergistic effect also occurs in the passivation of stainless steel by the addition of nitrogen and molybdenum [40], but this effect is due to the bipolarity of the passive film. As shown in Figure 1, coaddition of both nitrite and TEA was almost 30 times more effective than a single corrosion inhibitor (nitrite or TEA) in inhibiting corrosion of DCI. On the inhibited surface, the distributions of elements were similar, regardless of whether there was single addition of inhibitor (nitrite or TEA) or coaddition of inhibitors (nitrite and TEA). However, nitrite could form an oxide film, which exhibited high impedance and N-type semiconductive properties. In contrast, TEA could not for the oxide film. Thus, impedance and semiconductive properties were not exhibited in the absence of oxide film. This makes us wonder about the origin synergistic effect in these conditions.

Synergistic effect occurred when both nitrite and TEA were added to tap water. Thus, new materials might have been formed when both nitrite and TEA were added to tap water. Figure 9 shows FT-IR spectra obtained after the addition of inhibitors to distilled water. The concentrations of various inhibitors were as follows: $100,000 \mathrm{ppm} \mathrm{NO}_{2}{ }^{-}, 100,000 \mathrm{ppm}$ TEA, and 50,000 ppm $\mathrm{NO}_{2}{ }^{-}+50,000 \mathrm{ppm}$ TEA. In the case of coaddition, we increased the concentration to improve the sensitivity of FT-IR measurement. In all samples, the peaks appearing at $1,625 \mathrm{~cm}^{-1}$ are associated with the $\mathrm{H}-\mathrm{O}-\mathrm{H}$ bending vibration in $\mathrm{H}_{2} \mathrm{O}$ [41]. In 100,000 ppm nitrite sample, $\mathrm{NO}_{2}{ }^{-}$peak appears in $1,226 \mathrm{~cm}^{-1}$ [42]. In 100,000 ppm TEA sample, the peak at $1,024 \mathrm{~cm}^{-1}$ is attributed to C-N peak. In the case of 50,000 ppm $\mathrm{NaNO}_{2}+50,000 \mathrm{ppm}$ TEA sample, we could detect the following peaks: $\mathrm{H}-\mathrm{O}-\mathrm{H}$ bend peak, $\mathrm{NO}_{2}{ }^{-}$ peak, and C-N peak. No other peaks appeared in the FTIR spectrum of this sample. This finding established the fact that novel materials were not produced when nitrite and TEA were coadded to tap water. Furthermore, it is confirmed that synergistic effect was not related to the new materials formed by the coaddition of nitrite and TEA.

As shown in Figures 6, 7, and 8, the distribution of oxygen on the surface of DCI depends upon the type of corrosion inhibitor. When nitrite was added as an inhibition in tap water, oxygen was detected on both graphite and matrix. This implies that the matrix is oxidized by nitrite. Furthermore, nitrite is adsorbed on graphite. When TEA was added as an inhibitor in tap water, oxygen was mainly adsorbed on graphite: however, it is rarely adsorbed on the matrix. In contrast, when there was coaddition of nitrite and TEA in tap water, oxygen was easily detected on both graphite and the matrix. Thus, we infer that nitrite oxidized the matrix and TEA adsorbed on the graphite. Figure 10 shows XPS depth profile $((\mathrm{a}),(\mathrm{b})$, and $(\mathrm{c}))$ and N1s peaks $\left(\left(\mathrm{a}^{\prime}\right),\left(\mathrm{b}^{\prime}\right)\right.$, and $\left.\left(\mathrm{c}^{\prime}\right)\right)$ of the surface film formed in the following three conditions: ((a), $\left.\left(a^{\prime}\right)\right) 100,000 \mathrm{ppm} \mathrm{NO}_{2}{ }^{-}+$tap water, $\left((\mathrm{b}),\left(\mathrm{b}^{\prime}\right)\right)$ 100,000 ppm TEA + tap water, and $\left((\mathrm{c}),\left(\mathrm{c}^{\prime}\right)\right) 1,000 \mathrm{ppm} \mathrm{NO}{ }^{-}+2,500 \mathrm{ppm}$ TEA + tap water. In the case of nitrite or coaddition samples, O1s content gradually decreased with depth. But when only TEA was added to the sample, O1s content drastically reduced with depth. With these findings, we infer that oxygen was adsorbed on the outmost surface in the case of samples containing only added TEA. But, in the case of nitrite or coaddition samples, oxygen did form an oxide layer on the surface. On the other hand, as shown in Figures 6, 7, and 8, a small amount of nitrogen was detected only on the graphite. 


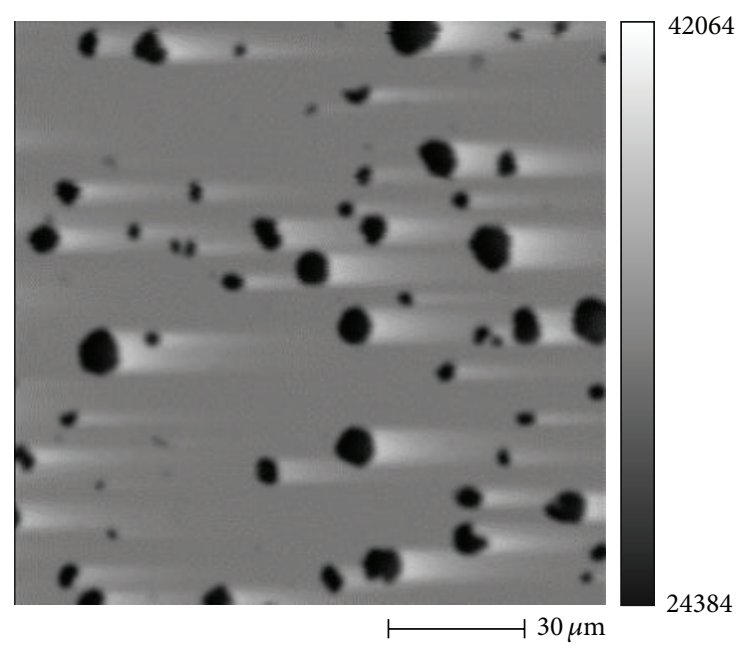

(a)

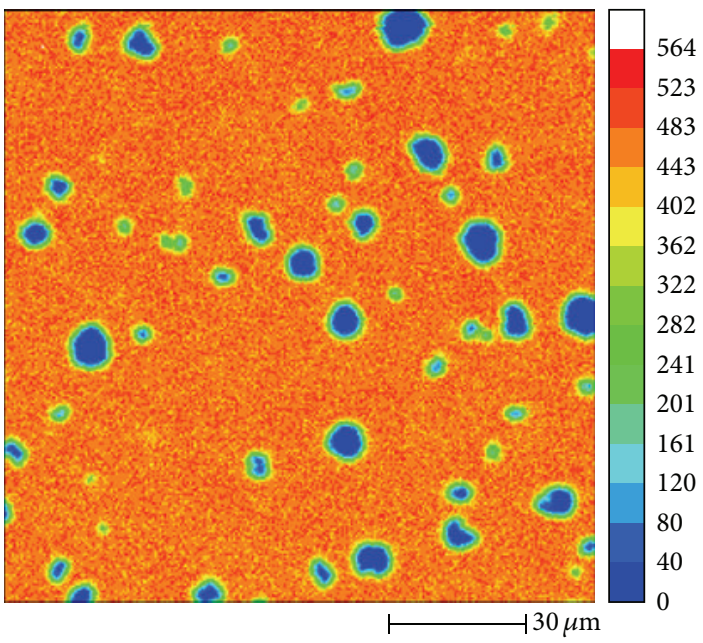

(b)

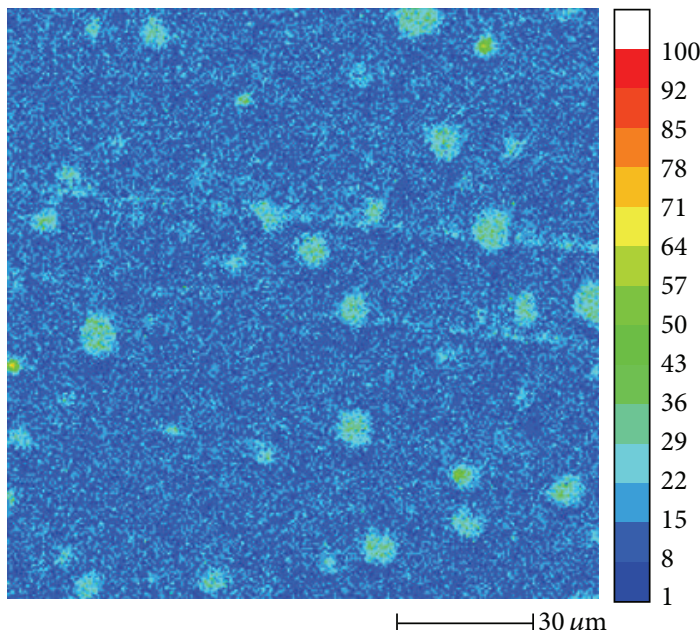

(d)

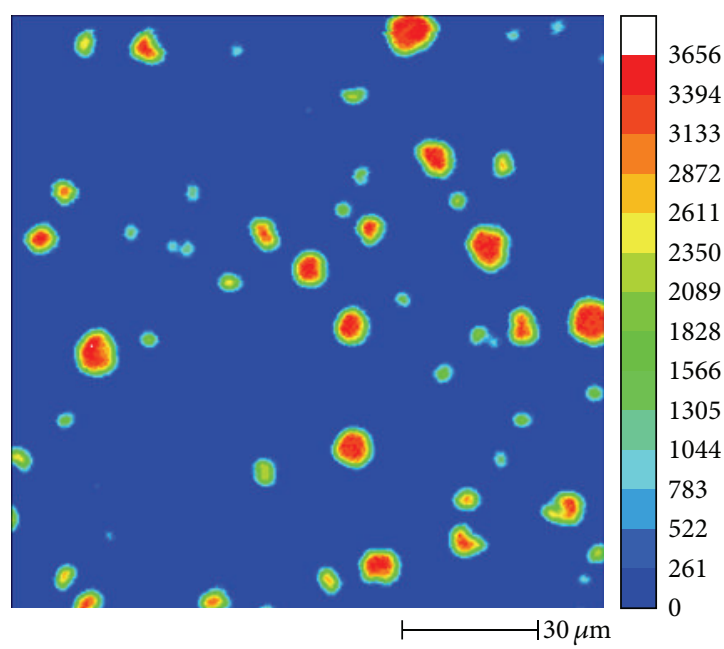

(c)

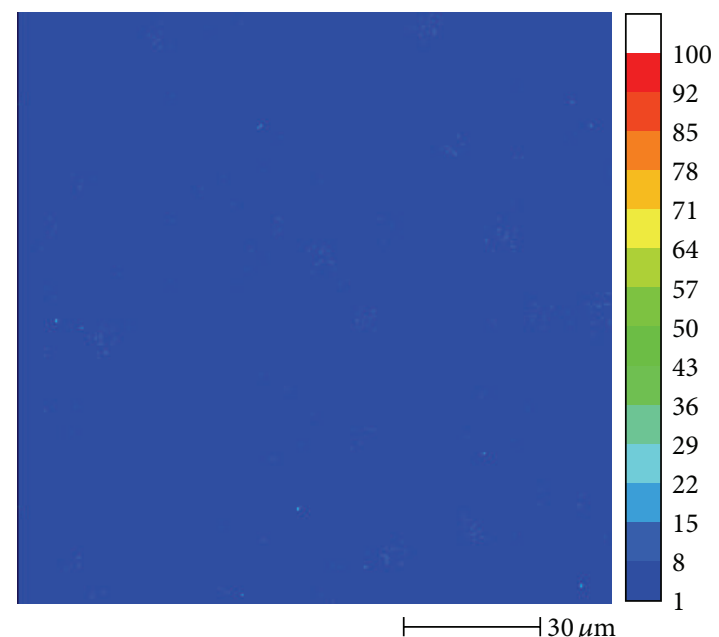

(e)

FIGURE 6: Elemental distribution analyzed by EPMA on the surface of DCI, which was passivated for 72 hours in tap water with 100k ppm $\mathrm{NO}_{2}{ }^{-}$addition at $25^{\circ} \mathrm{C}$. (a) SEM image, (b) Fe, (c) C, (d) O, and (e) $\mathrm{N}$ [12]. 


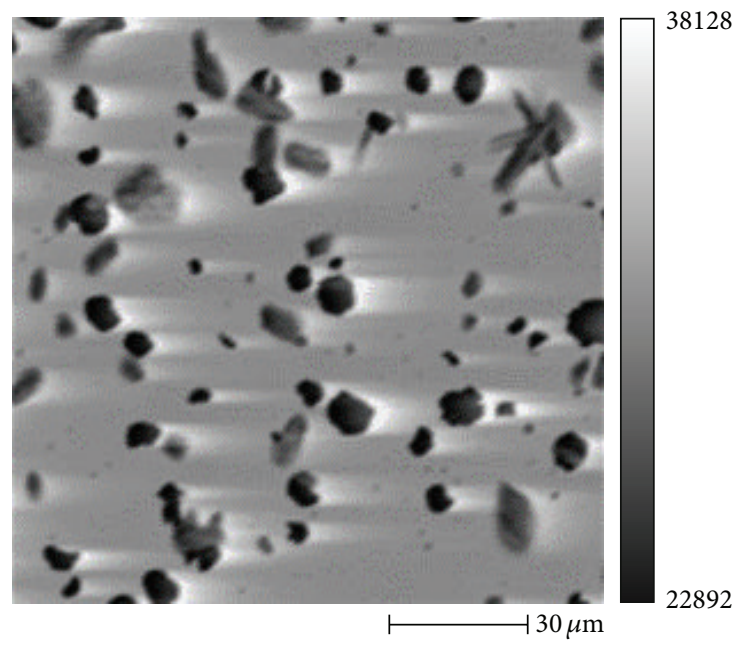

(a)

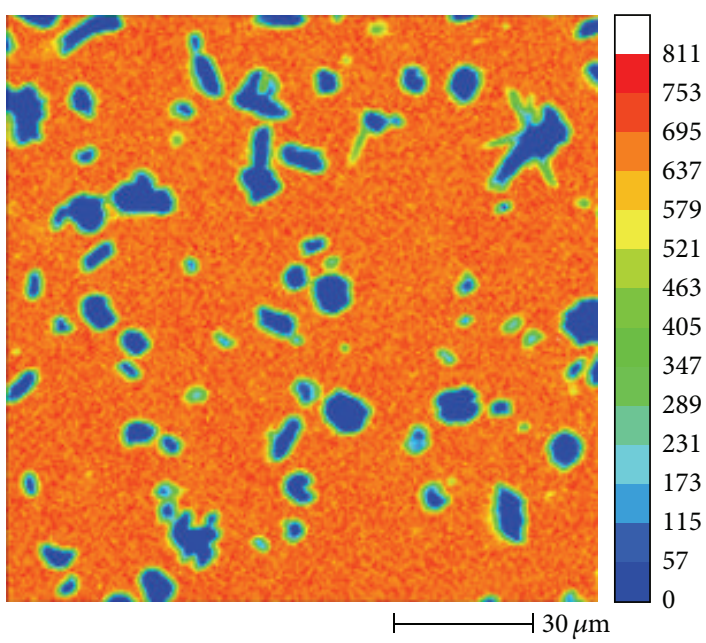

(b)

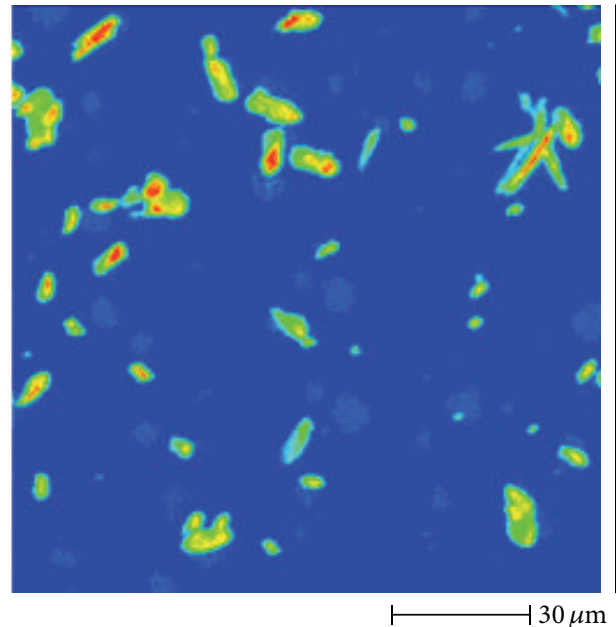

(d)

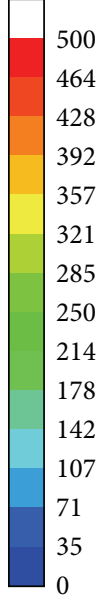

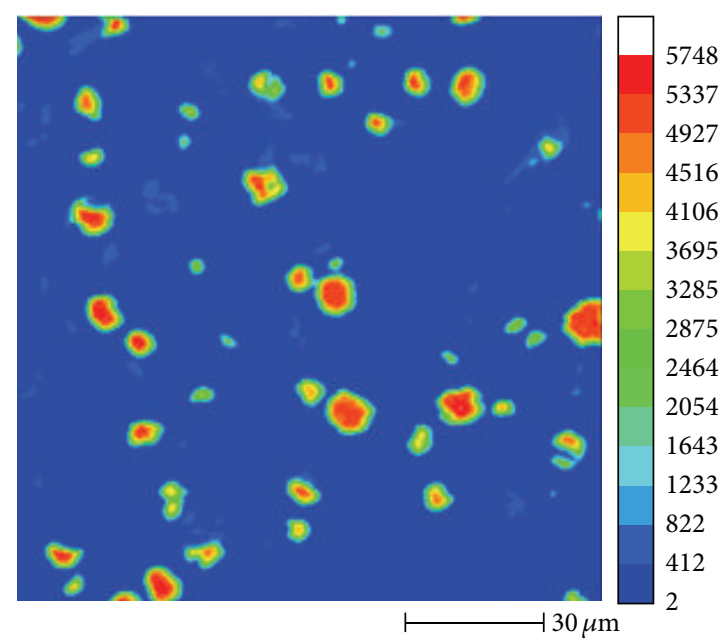

(c)

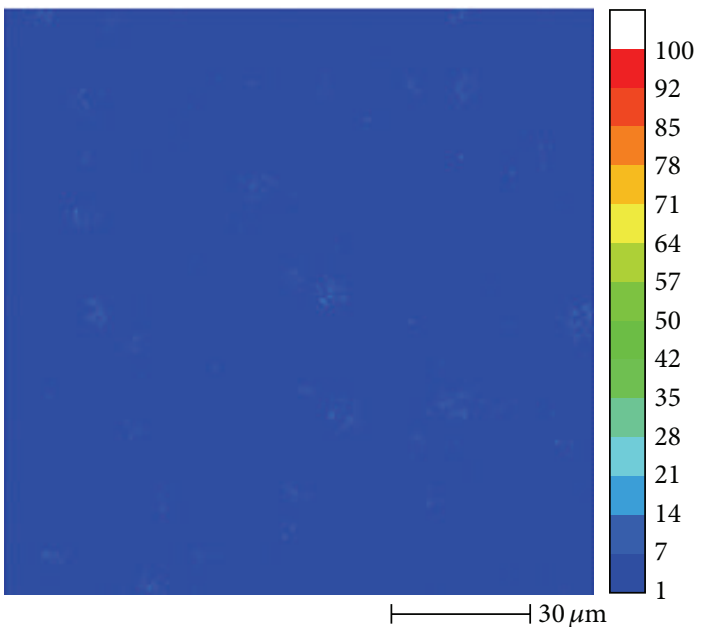

(e)

FIGURE 7: Elemental distribution analyzed by EPMA on the surface of DCI, which was passivated for 72 hours in tap water with $100 \mathrm{k}$ ppm TEA addition at $25^{\circ} \mathrm{C}$. (a) SEM image, (b) Fe, (c) C, (d) O, and (e) N. 


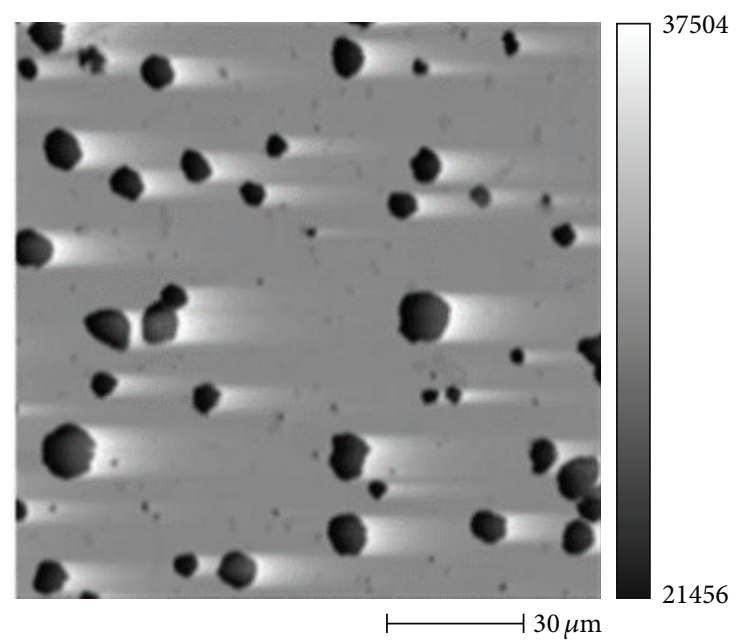

(a)

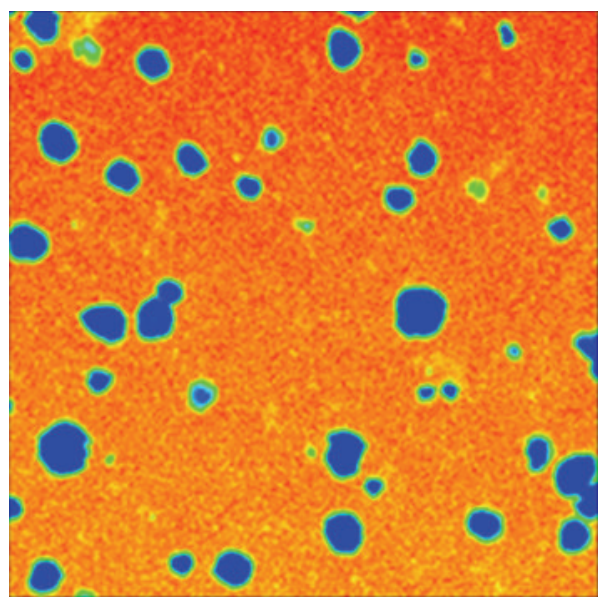

$\longmapsto 30 \mu \mathrm{m}$

(b)

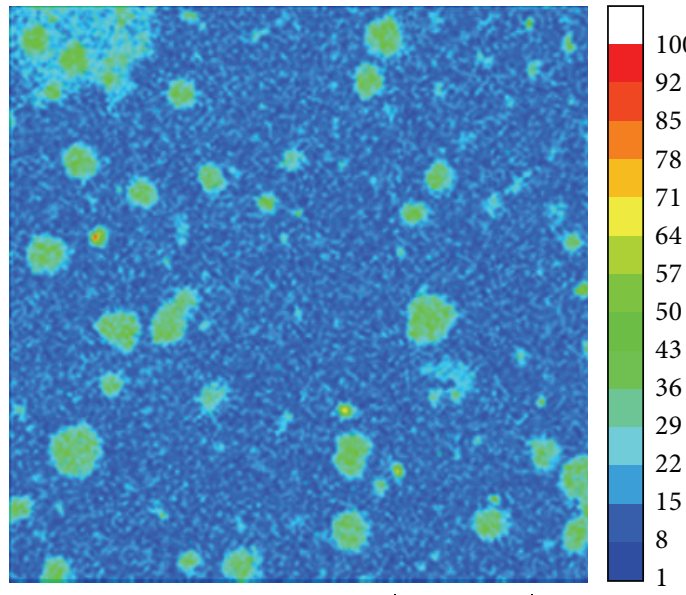

$\longmapsto 30 \mu \mathrm{m}$

(d)

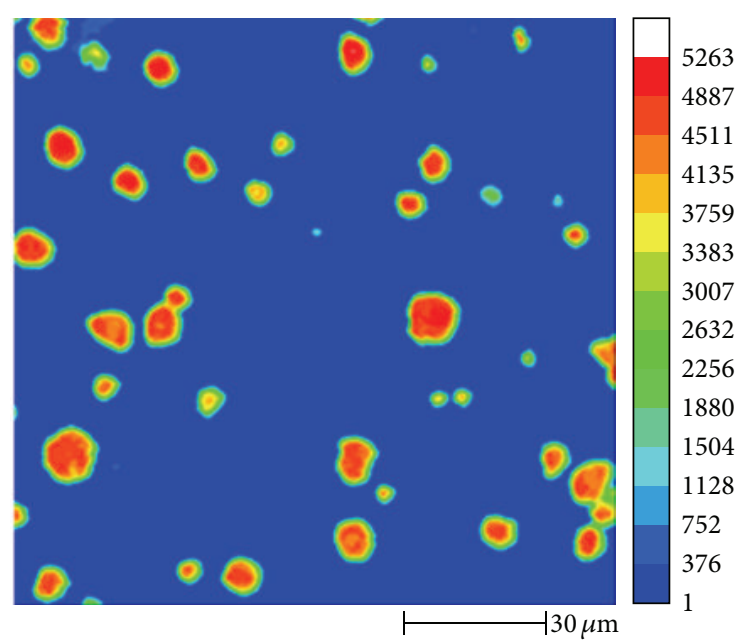

(c)

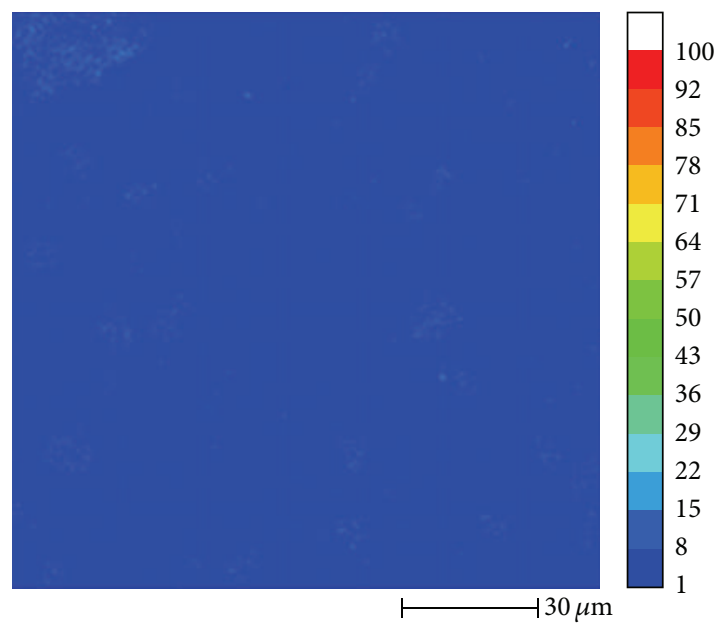

(e)

FIGURE 8: Elemental distribution analyzed by EPMA on the surface of DCI, which was passivated for 72 hours in tap water with $1 \mathrm{kppm} \mathrm{NO}_{2}^{-}$ $+2.5 \mathrm{k} \mathrm{ppm} \mathrm{TEA}$ at $25^{\circ} \mathrm{C}$. (a) SEM image, (b) Fe, (c) C, (d) O, and (e) N. 


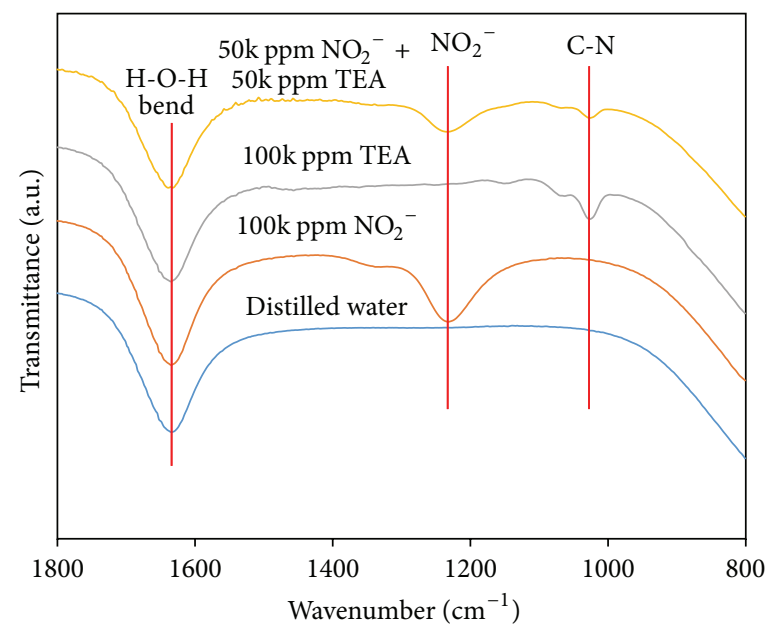

FIGURE 9: FT-IR spectra representing the effect of increasing concentrations of inhibitor in distilled water.

Figures $10\left(\mathrm{a}^{\prime}\right), 10\left(\mathrm{~b}^{\prime}\right)$, and $10\left(\mathrm{c}^{\prime}\right)$ illustrate the chemical state of N1s. In the case of sample containing only added nitrite (Figure 10 $\left(\mathrm{a}^{\prime}\right)$ ), N1s (its binding energy was around $400 \mathrm{eV}$ ) was detected only at the outmost surface. Moreover, N1s was not detected by sputtering. In the case of samples containing only added TEA (Figure $10\left(b^{\prime}\right)$ ), N1s (its binding energy was around $405 \mathrm{eV}$ ) was detected only at the outmost surface: N1s was not detected by sputtering (it should be noted that, around $405 \mathrm{eV}, \mathrm{N} 1 \mathrm{~s}$ was not due to the presence of nitrite or nitrate: the appearance of N1s was attributed to the presence of N-C bond in TEA). However, in the case of coaddition (Figure 10 $\left(c^{\prime}\right)$ ), N1s (its binding energies were around $400 \mathrm{eV}$ and $406 \mathrm{eV}$ ) was detected only at the outmost surface: N1s was not detected by sputtering. Therefore, it is confirmed that nitrogen is also adsorbed on the outmost surface. This finding completely agrees with the result of EPMA analysis.

In addition to the chemical composition of the surface, the surface properties associated with single addition and coaddition of inhibitors should be compared. Figure 11 shows the effect of corrosion inhibitors on Mott-Schottky plot representing the passive film formed at $0 \mathrm{~V}$ (SCE) in deaerated tap water at $25^{\circ} \mathrm{C}$. As described earlier, the addition of only nitrite led to development of excellent semiconductive properties in the medium, but the single TEA could not develop any semiconductive properties. However, in the case of coaddition, small capacitance was built up. Figure 12 compared the effect of addition sequence of corrosion inhibitors on AC impedance of the passive film that was formed at $0 \mathrm{~V}$ (SCE) in deaerated tap water at $25^{\circ} \mathrm{C}$. The coaddition of nitrite and TEA had the highest polarization resistance: the specimen was first immersed in tap water containing 1,000 ppm nitrite. Then, 2,500 ppm TEA addition was added to this tap water that already contained $1,000 \mathrm{ppm}$ nitrite. Under these conditions, the specimen developed high polarization resistance. However, the specimen exhibited very low polarization resistance in the following conditions: the specimen was immersed in tap water containing 2,500 ppm TEA, and then 1,000 ppm nitrite was added to this tap water that already contained
2,500 ppm TEA. This behavior indicates that, regardless of the addition sequence, the presence of nitrite can make the surface oxidizing: however, if the specimen is first exposed to TEA solution, the subsequent addition of nitrite cannot bring about the oxidation of metallic surface. Therefore, it should be noted that synergistic effect depends upon the addition sequence of corrosion inhibitors.

In summary, we propose the corrosion inhibiting mechanisms associated with single addition or coaddition. Figure 13 illustrates newly proposed mechanisms that inhibit corrosion. In the case of samples containing only added nitrite, the mechanism has been described elsewhere in detail [12]. Although the concentration of nitrite is not sufficient, nitrite can oxidize the metallic matrix. However, galvanic corrosion between graphite and matrix continues to occur. If nitrite is added in large quantity, the excessive nitrite can cover the surface of graphite. Finally, at some stage, the entire surface would get covered with nitrite compound: the oxide film would also be covered by nitrite. In the case of samples containing only added TEA, at inadequate concentrations of TEA, TEA is adsorbed on graphite selectively. Therefore, galvanic corrosion continues to occur between graphite and the matrix. If the amount of added TEA is increased steadily, the excessive TEA can cover the surface of graphite. Finally, the whole surface will be covered with TEA layer, and this layer would act as the barrier layer. However, in the case of coaddition, synergistic effect occurs by the following process: among the two inhibitors, nitrite oxidizes the metallic surface. TEA simultaneously adsorbs at the graphite surface and this adsorbed layer acts as the barrier layer: this layer mitigates the galvanic corrosion that occurs between graphite and matrix. Thus, the synergistic effect occurs finally.

\section{Conclusions}

(1) Although the addition of only nitrite is not sufficient, nitrite can oxidize the metallic matrix. But galvanic corrosion still occurs between graphite and matrix. 

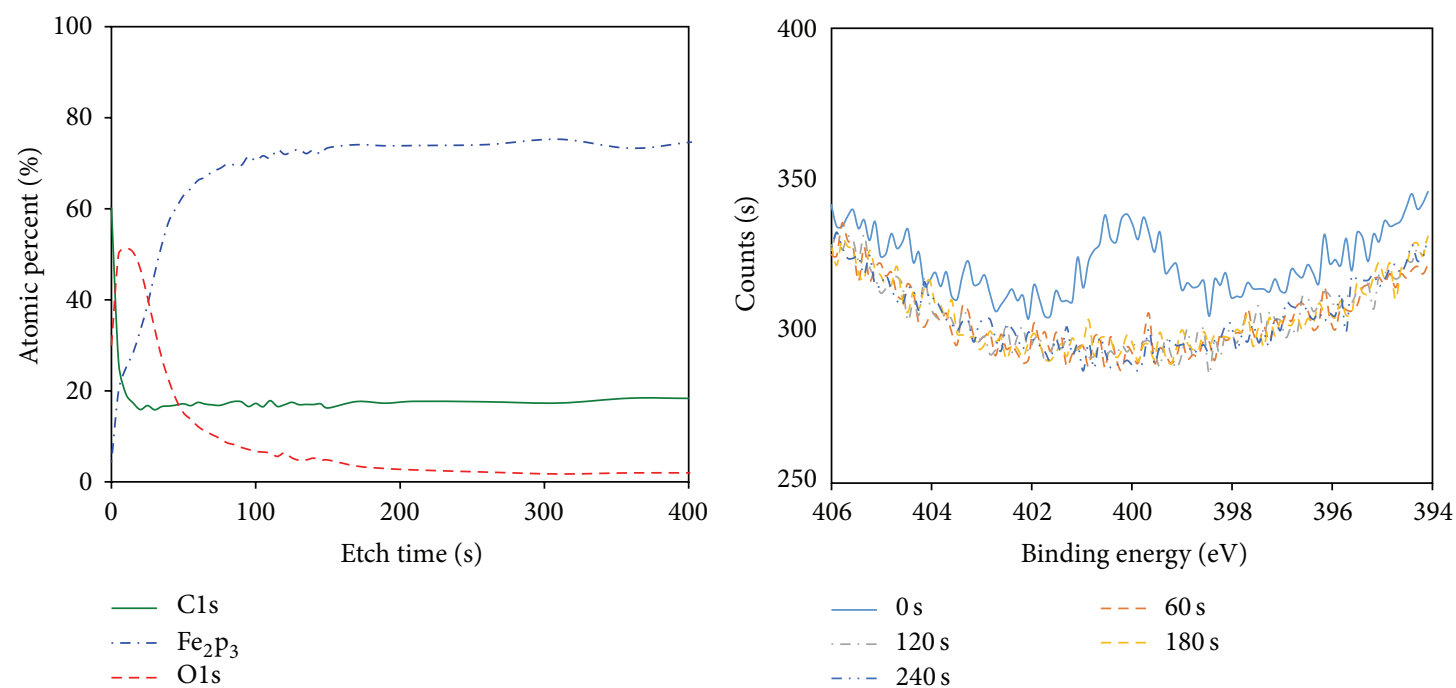

(a)

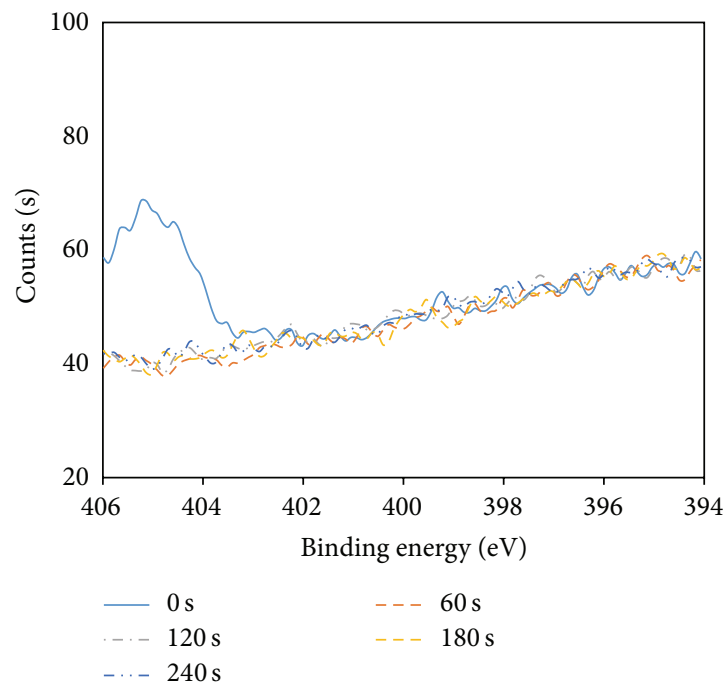

(b)

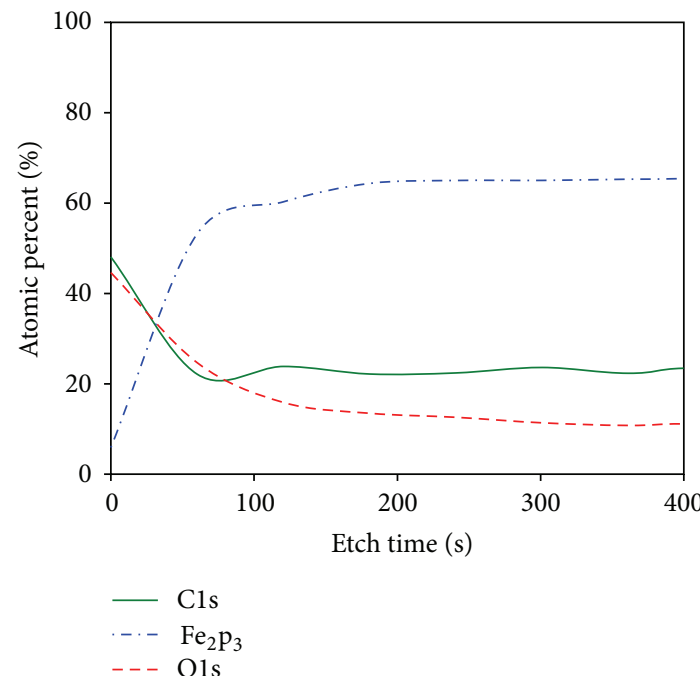

(c)

$\left(b^{\prime}\right)$

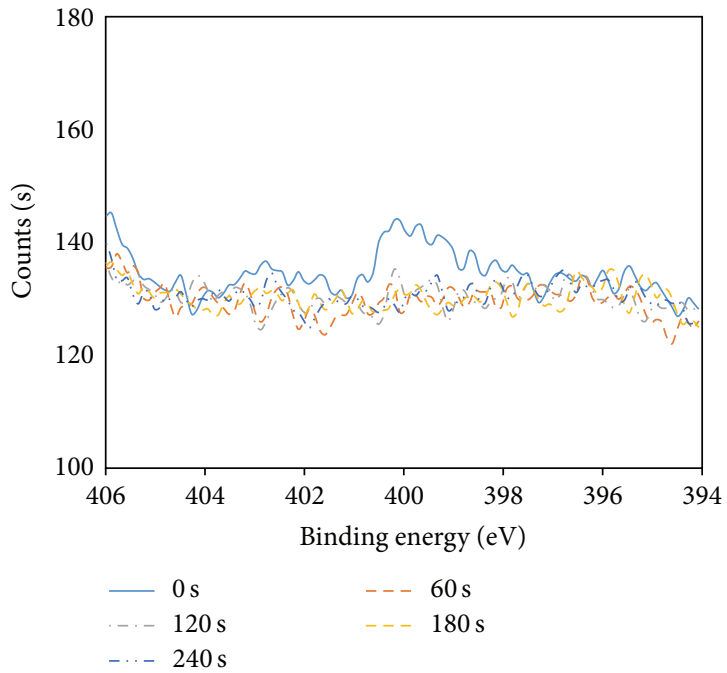

$\left(c^{\prime}\right)$

Figure 10: XPS depth profile ((a), (b), and (c)) and N1s peaks $\left(\left(\mathrm{a}^{\prime}\right),\left(\mathrm{b}^{\prime}\right)\right.$, and $\left.\left(\mathrm{c}^{\prime}\right)\right)$ of the surface film formed in $\left((\mathrm{a}),\left(\mathrm{a}^{\prime}\right)\right) 100 \mathrm{kppm} \mathrm{NO}_{2}{ }^{-}+$ tap water, $\left((\mathrm{b}),\left(\mathrm{b}^{\prime}\right)\right) 100 \mathrm{kppm}$ TEA + tap water, and $\left((\mathrm{c}),\left(\mathrm{c}^{\prime}\right)\right) 1 \mathrm{kppm} \mathrm{NO}_{2}{ }^{-}+2.5 \mathrm{kppm} \mathrm{TEA}+$ tap water. 


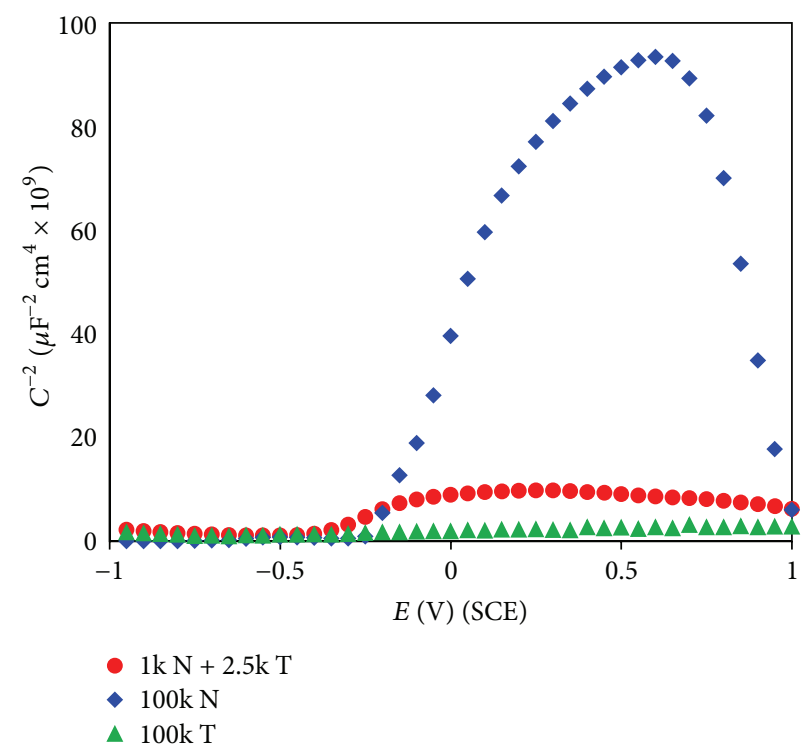

FIGURE 11: Effect of corrosion inhibitors (N: ppm $\mathrm{NO}_{2}{ }^{-}$, T: ppm TEA) on Mott-Schottky plot for the passive film formed at $0 \mathrm{~V}$ (SCE) in deaerated tap water at $25^{\circ} \mathrm{C}$.

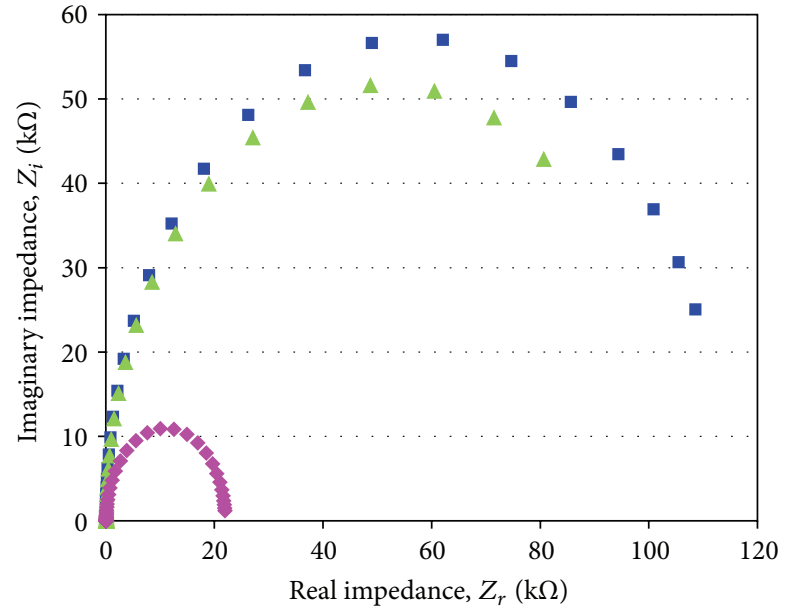

- $1 \mathrm{k} \mathrm{N}+2.5 \mathrm{k} \mathrm{T}$

$\Delta 1 \mathrm{k} \mathrm{N} \rightarrow 2.5 \mathrm{kT}$

- $2.5 \mathrm{k} \mathrm{T} \rightarrow 1 \mathrm{k} \mathrm{N}$

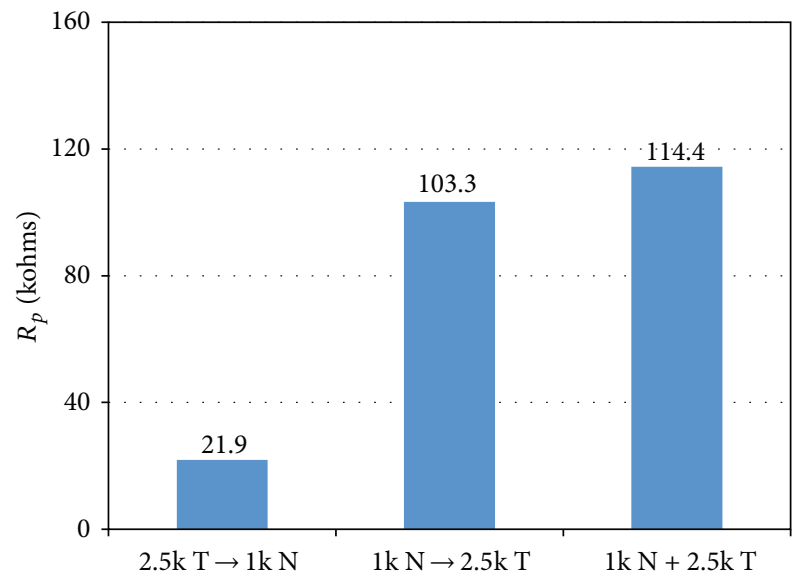

(a)

(b)

FIGURE 12: Effect of addition sequence of corrosion inhibitors ( $\mathrm{N}: \mathrm{ppm} \mathrm{NO}_{2}{ }^{-}$, T: ppm TEA) on AC impedance of the passive film that was formed at $0 \mathrm{~V}$ (SCE) in deaerated tap water at $25^{\circ} \mathrm{C}$. (a) Nyquist plot. (b) $R_{p}$.

If increasing amounts of nitrite are added, then the excessive nitrite can cover the surface of graphite. Finally, the entire surface can be covered with nitrite compound: the oxide film can be covered by nitrite. Furthermore, although the addition of only TEA is not sufficient, TEA adsorbs on graphite selectively. Nevertheless, galvanic corrosion between graphite and matrix still occurs. If increasing amounts of TEA are added, the excessive TEA can cover the surface of graphite. Finally, the entire surface can be covered with TEA layer, and this layer acts as the barrier layer.
(2) Owing to the synergistic effect of nitrite and TEA, there was effective inhibition of corrosion of DCI in tap water: the inhibitory effect was $c a .30$ times more effective than that witnessed with single additions. This synergistic effect occurs by the following process: among the two inhibitors, nitrite oxidizes the metallic surface. On the other hand, TEA gets adsorbed simultaneously at the graphite surface. This adsorbed layer acts as the barrier layer that mitigates the galvanic corrosion between graphite and matrix. Finally, synergistic effect is achieved. 

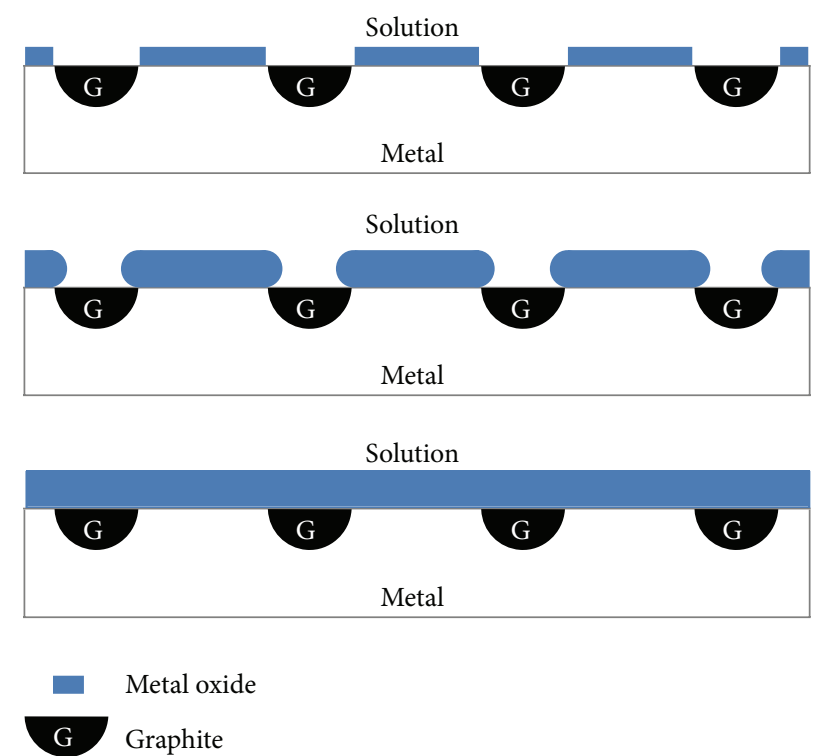
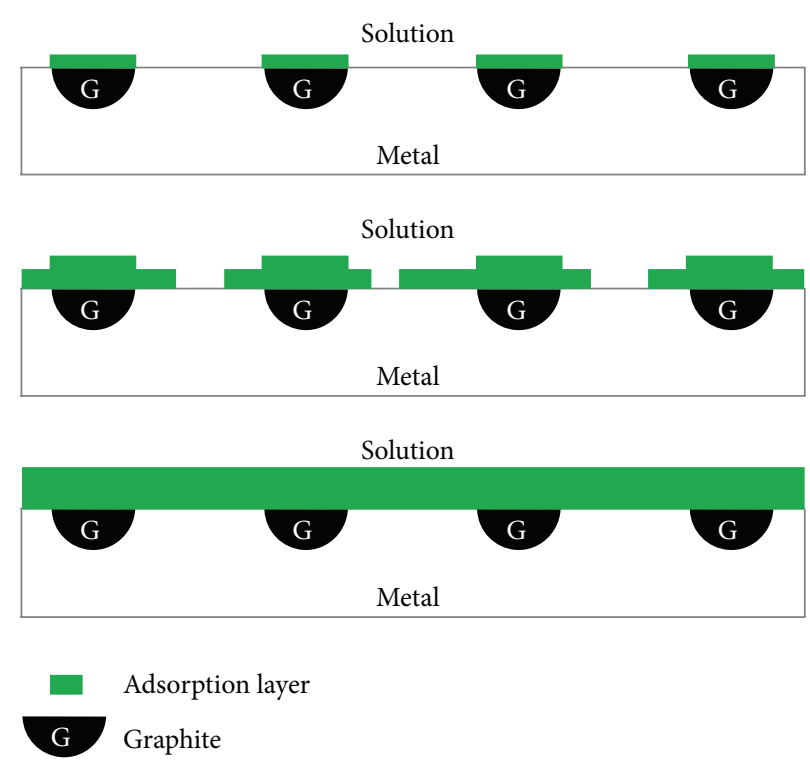

G Graphite

(a)

(b)
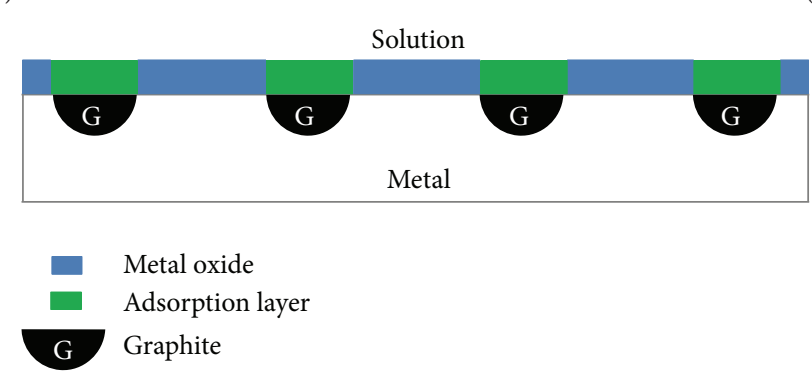

(c)

FIGURE 13: Newly proposed corrosion inhibiting mechanisms. (a) nitrite single addition [12], (b) TEA single addition, and (c) coaddition of nitrite + TEA.

\section{Competing Interests}

The authors declare that there is no conflict of interests regarding the publication of this article.

\section{Acknowledgments}

This work was supported by the Nuclear Power Core Technology Development Program of the Korea Institute of Energy Technology Evaluation and Planning (KETEP) granted financial resource from the Ministry of Trade, Industry \& Energy, Republic of Korea (no. 20131520000100).

\section{References}

[1] EPRI, "Nondestructive evaluation; Guided wave technology development and nuclear application assessment," EPRI 1015156, 2007.

[2] E. McCafferty, Introduction to Corrosion Science, Springer, New York, NY, USA, 2010.

[3] V. S. Sastri, Corrosion Inhibitors: Principles and Applications, John Wiley \& Sons, London, UK, 1998.

[4] K. N. Mohana and A. M. Badiea, "Effect of sodium nitrite-borax blend on the corrosion rate of low carbon steel in industrial water medium," Corrosion Science, vol. 50, no. 10, pp. 2939-2947, 2008.

[5] B. N. Popov, Corrosion Engineering; Principles and Solved Problems, Elsevier, Waltham, Mass, USA, 2015.

[6] S. W. Dean Jr., R. Derby, and G. T. Von Dem Bussche, "Inhibitor type," Materials Performance, vol. 20, no. 12, pp. 47-51, 1981.

[7] L. Wang, "Evaluation of 2-mercaptobenzimidazole as corrosion inhibitor for mild steel in phosphoric acid," Corrosion Science, vol. 43, no. 12, pp. 2281-2289, 2001.

[8] M. A. Quraishi and R. Sardar, "Aromatic triazoles as corrosion inhibitors for mild steel in acidic environments," Corrosion, vol. 58, no. 9, pp. 748-755, 2002.

[9] F. Bentiss, M. Lebrini, H. Vezin, and M. Lagrenée, "Experimental and theoretical study of 3-pyridyl-substituted 1,2,4thiadiazole and 1,3,4-thiadiazole as corrosion inhibitors of mild steel in acidic media," Materials Chemistry and Physics, vol. 87, no. 1, pp. 18-23, 2004.

[10] E. A. Noor, "The inhibition of mild steel corrosion in phosphoric acid solutions by some $\mathrm{N}$-heterocyclic compounds in the salt form," Corrosion Science, vol. 47, no. 1, pp. 33-55, 2005.

[11] G. Trabanelli, Corrosion Inhibitors, Edited by F. Mansfield, Marcel Dekker, New York, NY, USA, 1970.

[12] K. T. Kim, H. W. Kim, H. Y. Chang, B. T. Lim, H. B. Park, and Y. S. Kim, "Corrosion inhibiting mechanism of nitrite ion on 
the passivation of carbon steel and ductile cast iron for nuclear power plants," Advances in Materials Science and Engineering, vol. 2015, Article ID 408138, 16 pages, 2015.

[13] H. D. Yeon, A study on the corrosion behavior with corrosion inhibitor on nitrite and hydrazine in SA106 Gr.B and SA516-70 carbon steel [M.S. thesis], Chungnam National University, 2011.

[14] I. H. Farooqi, P. A. Saini, and M. A. Quraishi, "Recent trends in cooling water inhibitors," in Proceedings of the CORROSION, Paper no. 00332, NACE, 2000.

[15] M. Cohen, "Inhibition of steel Corrosion by sodium nitrite in water," Journal of Electrochemical Society, vol. 93, no. 1, pp. 2639, 1948.

[16] R. Pyke and M. Cohen, "Rate of breakdown and mechanism of nitrite inhibition of steel corrosion," Journal of the Electrochemical Society, vol. 93, no. 3, pp. 63-78, 1948.

[17] M. Cohen, R. Pyke, and P. Marier, "The effect of oxygen on inhibition of corrosion by nitrite," Journal of Electrochemical Society, vol. 96, no. 4, pp. 254-261, 1949.

[18] S. Matsuda and H. H. Uhlig, "Effect of $\mathrm{pH}$, sulfates, and chlorides on behavior of sodium chromate and nitrite as passivators for steel," Journal of the Electrochemical Society, vol. 111, no. 2, pp. 156-161, 1964.

[19] W. D. Robertson, "Molybdate and tungstate as corrosion inhibitors and the mechanism of inhibition," Journal of the Electrochemical Society, vol. 98, no. 3, pp. 94-100, 1951.

[20] M. J. Pryor and M. Cohen, "The inhibition of the corrosion of iron by some anodic inhibitors," Journal of Electrochemical Society, vol. 100, no. 5, pp. 203-215, 1953.

[21] S. Karim, C. M. Mustafa, M. Assaduzzaman, and M. Islam, "Effect of nitrate ion on corrosion inhibition of mild steel in simulated cooling water," Chemical Engineering Research Bulletin, vol. 14, no. 2, pp. 87-91, 2010.

[22] Y. T. Horng and Y. L. Tsai, "An investigation of mild steel with nitrogen-containing inhibitor in hydrochloric acid," Corrosion Science and Technology, vol. 2, no. 5, pp. 233-237, 2003.

[23] I. Carrillo, B. Valdez, R. Zlatev, M. Stoytcheva, M. Carrillo, and R. Bäbler, "Electrochemical study of oxyanions effect on galvanic corrosion inhibition," International Journal of Electrochemical Science, vol. 7, no. 9, pp. 8688-8701, 2012.

[24] J. O. Okeniyi, A. P. I. Popoola, C. A. Loto, O. A. Omotosho, S. O. Okpala, and I. J. Ambrose, "Effect of $\mathrm{NaNO}_{2}$ and $\mathrm{C}_{6} \mathrm{H}_{15} \mathrm{NO}_{3}$ synergistic admixtures on steel-rebar corrosion in concrete immersed in aggressive environments," Advances in Materials Science and Engineering, vol. 2015, Article ID 540395, 11 pages, 2015.

[25] A. M. Ridhwan, A. A. Rahim, and A. M. Shah, "Synergistic effect of halide ions on the corrosion inhibition of mild steel in hydrochloric acid using mangrove tannin," International Journal of Electrochemical Science, vol. 7, no. 9, pp. 8091-8104, 2012.

[26] M. Vishnudevan, "Synergistic influence of nitrite on inhibition of mild steel corrosion in chloride contaminated alkaline solution," Iranian Journal of Materials Science and Engineering, vol. 9, no. 4, pp. 17-27, 2012.

[27] M. Bouklah, A. Attayibat, B. Hammouti, A. Ramdani, S. Radi, and M. Benkaddour, "Pyridine-pyrazole compound as inhibitor for steel in $1 \mathrm{M} \mathrm{HCl}$," Applied Surface Science, vol. 240, no. 1-4, pp. 341-348, 2005.

[28] K. F. Khaled, "An electrochemical study for corrosion inhibition of iron by some organic phosphonium chloride derivatives in acid media," Applied Surface Science, vol. 230, no. 1-4, pp. 307318, 2004.
[29] S. A. Umoren, O. Ogbobe, I. O. Igwe, and E. E. Ebenso, "Inhibition of mild steel corrosion in acidic medium using synthetic and naturally occurring polymers and synergistic halide additives," Corrosion Science, vol. 50, no. 7, pp. 1998-2006, 2008.

[30] L. Niu, H. Zhang, F. Wei, S. Wu, X. Cao, and P. Liu, "Corrosion inhibition of iron in acidic solutions by alkyl quaternary ammonium halides: correlation between inhibition efficiency and molecular structure," Applied Surface Science, vol. 252, no. 5, pp. 1634-1642, 2005.

[31] R. Guo, T. Q. Liu, and X. Wei, "Effects of SDS and some alcohols on the inhibition efficiency of corrosion for nickel," Colloids and Surfaces A: Physicochemical and Engineering Aspects, vol. 209, no. 1, pp. 37-45, 2002.

[32] S. T. Keera and M. A. Deyab, "Effect of some organic surfactants on the electrochemical behaviour of carbon steel in formation water," Colloids and Surfaces A: Physicochemical and Engineering Aspects, vol. 266, no. 1-3, pp. 129-140, 2005.

[33] T. Y. Soror and M. A. El-Ziady, "Effect of cetyl trimethyl ammonium bromide on the corrosion of carbon steel in acids," Materials Chemistry and Physics, vol. 77, no. 3, pp. 697-703, 2003.

[34] M. L. Free, "Understanding the effect of surfactant aggregation on corrosion inhibition of mild steel in acidic medium," Corrosion Science, vol. 44, no. 12, pp. 2865-2870, 2002.

[35] H. Ma, S. Chen, B. Yin, S. Zhao, and X. Liu, "Impedance spectrospic study of corrosion inhibition of copper by surfactants in the acidic solutions," Corrosion Science, vol. 45, no. 5, pp. 867882, 2003.

[36] Korean Agency for Technology and Standards, KS D4311 Ductile Iron Pipe, Korean Agency for Technology and Standards, Gyeonggi-do, Republic of Korea, 2010.

[37] D. D. Macdonald, "Point defect model for the passive state," Journal of the Electrochemical Society, vol. 139, no. 12, pp. 34343449, 1992.

[38] L. Abosrra, M. Youseffi, and A. F. Ashour, "Effectiveness of calcium nitrite in retarding corrosion of steel in concrete," International Journal of Concrete Structures and Materials, vol. 5, no. 1, pp. 65-73, 2011.

[39] S. Karim, C. M. Mustafa, Md. Assaduzzaman, and M. Islam, "Effect of nitrate ion on corrosion inhibition of mild steel in simulated cooling water," Chemical Engineering Research Bulletin, vol. 14, no. 2, pp. 87-91, 2010.

[40] Y. S. Kim, "Synergistic effect of nitrogen and molybdenum on localized corrosion of stainless steel," Corrosion Science and Technology, vol. 9, no. 1, pp. 20-28, 2010.

[41] B. L. Mojet, S. D. Ebbesen, and L. Lefferts, "Light at the interface: the potential of attenuated total reflection infrared spectroscopy for understanding heterogeneous catalysis in water," Chemical Society Reviews, vol. 39, no. 12, pp. 4643-4655, 2010.

[42] M. Pandiarajan, S. Rajendran, J. Sathiya Bama, and R. Joseph Rathish, "Sodium nitrite as corrosion inhibitor for mild steel in simulated concrete pore solution," Journal of Chemical and Pharmaceutical Research, vol. 7, pp. 120-126, 2015. 

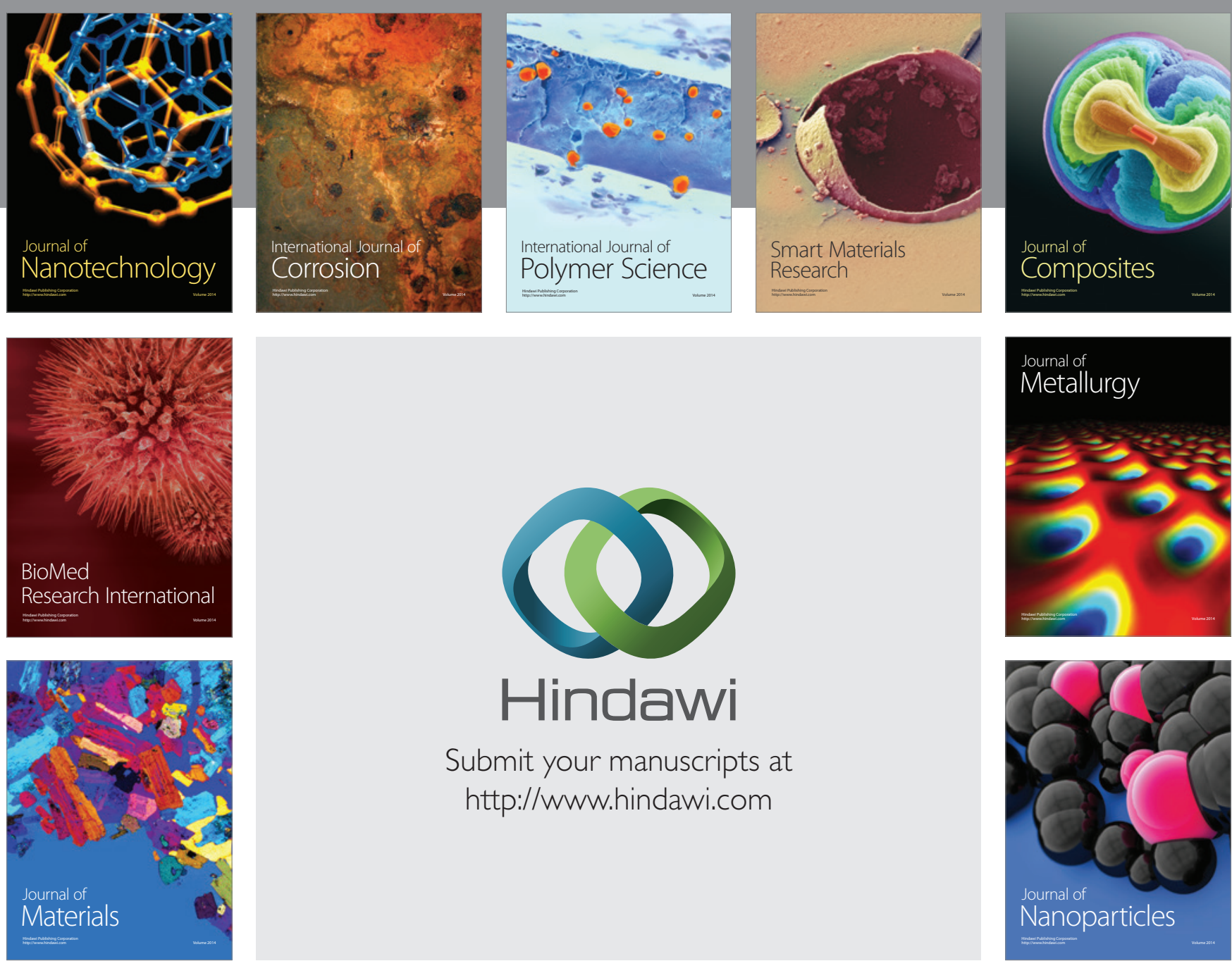

\section{Hindawi}

Submit your manuscripts at

http://www.hindawi.com

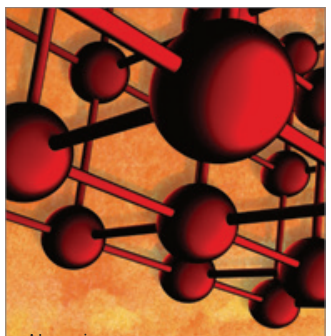

Materials Science and Engineering
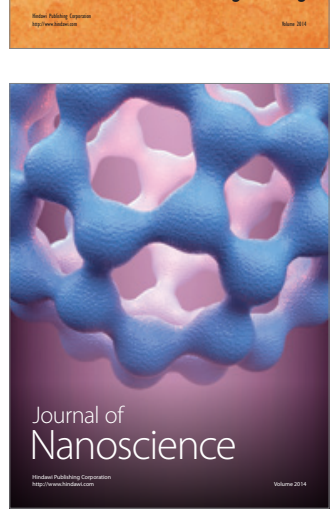
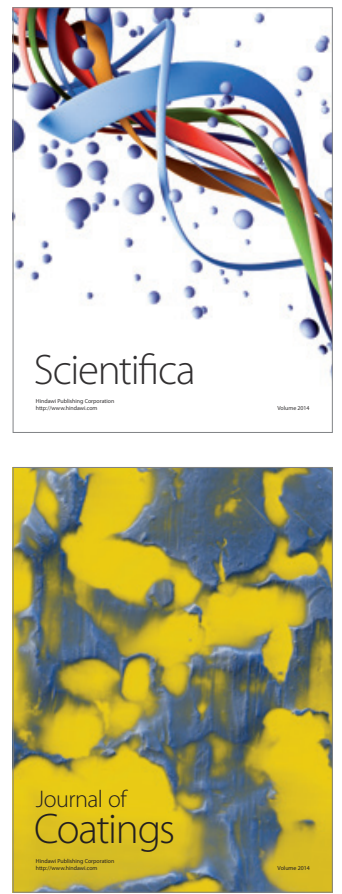
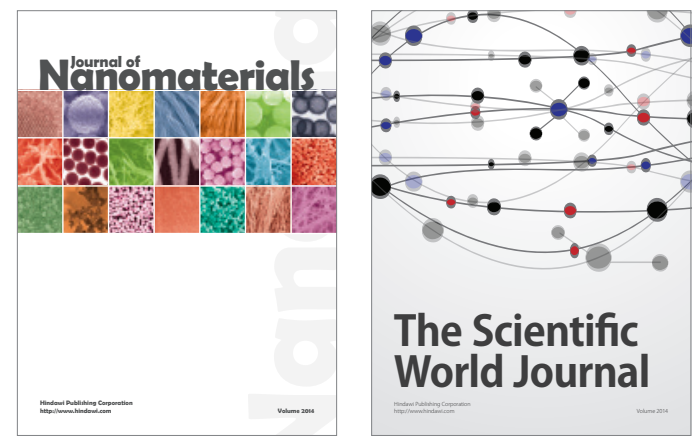

The Scientific World Journal
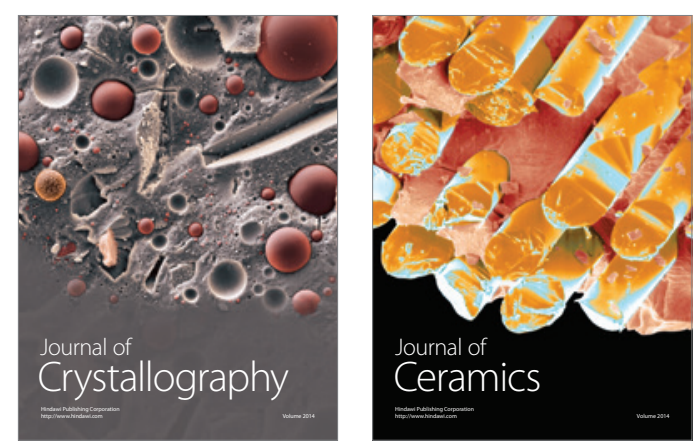
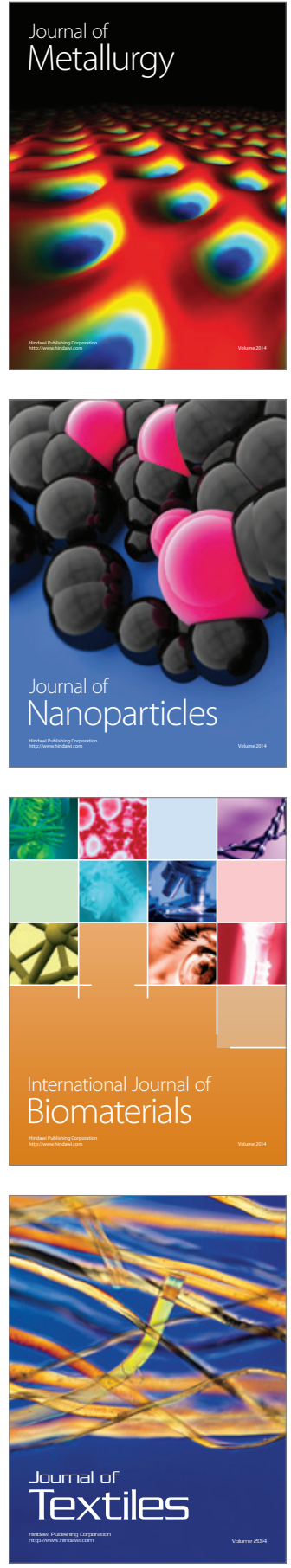